\title{
The Role of Telomerase Protein TERT in Alzheimer's Disease and in Tau-Related Pathology In Vitro
}

\author{
Alison Spilsbury, ${ }^{1,2}$ Satomi Miwa, ${ }^{1,2}$ Johannes Attems, ${ }^{1,3}$ and $\mathbb{C G}^{-}$abriele Saretzki $\mathbf{i}^{1,2}$ \\ ${ }^{1}$ Newcastle University Institute for Ageing, Campus for Ageing and Vitality, ${ }^{2}$ Institute for Cell and Molecular Bioscience, and ${ }^{3}$ Institute of Neuroscience, \\ Newcastle University, Newcastle upon Tyne, NE4 5PL, UK
}

The telomerase reverse transcriptase protein TERT has recently been demonstrated to have a variety of functions both in vitro and in vivo, which are distinct from its canonical role in telomere extension. In different cellular systems, TERT protein has been shown to be protective through its interaction with mitochondria. TERT has previously been found in rodent neurons, and we hypothesize that it might have a protective function in adult human brain. Here, we investigated the expression of TERT at different stages of Alzheimer's disease pathology (Braak Stages I-VI) in situ and the ability of TERT to protect against oxidative damage in an in vitro model of tau pathology. Our data reveal that TERT is expressed in vitro in mouse neurons and microglia, and in vivo in the cytoplasm of mature human hippocampal neurons and activated microglia, but is absent from astrocytes. Intriguingly, hippocampal neurons expressing TERT did not contain hyperphosphorylated tau. Vice versa, neurons that expressed high levels of pathological tau did not appear to express TERT protein. TERT protein colocalized with mitochondria in the hippocampus of Alzheimer's disease brains (Braak Stage VI), as well as in cultured neurons under conditions of oxidative stress. Our in vitro data suggest that the absence of TERT increases ROS generation and oxidative damage in neurons induced by pathological tau. Together, our findings suggest that TERT protein persists in neurons of the adult human brain, where it may have a protective role against tau pathology.

Key words: Alzheimer's disease; mitochondria; neuroprotection; oxidative stress; tau; telomerase

\section{Introduction}

Alzheimer's disease (AD) is a progressive neurodegenerative condition affecting $>35$ million individuals worldwide (Selkoe, 2012). Accumulation of both hyperphosphorylated (Alonso et al., 1996) and truncated (Basurto-Islas et al., 2008) microtubuleassociated tau protein into neurofibrillary tangles (NFTs) and neuropil threads (NTs) is a pathological hallmark of AD (Alonso et al., 1996). These tau forms cause disrupted axonal trafficking of mitochondria (Stamer et al., 2002; Dubey et al., 2008; Reddy, 2011) and impair respiration (Rhein et al., 2009), eventually leading to cell death (Yang et al., 2003). The gray matter is dense with

Received July 17, 2014; revised Dec. 4, 2014; accepted Dec. 11, 2014.

Author contributions: G.S. designed research; A.S., S.M., and G.S. performed research; A.S. and J.A. analyzed data; A.S., J.A., and G.S. wrote the paper.

This work was supported by Dunhill Medical Trust Grant SA15/1111 to G.S. Tissue for this study was provided by the Newcastle Brain Tissue Resource, which is funded in part by UK Medical Research Council Grant G0400074 and by Brains for Dementia Research, a joint venture between Alzheimer's Society and Alzheimer's Research UK. We thank J. Goetz (University of Queensland, Brisbane, Australia) for the kind gift of the P301L mutant tau plasmid; Glyn Nelson (Institute for Cell and Molecular Bioscience, Newcastle University) for technical assistance with the lentiviral construction; Ros Hall and Mary Johnson (Institute of Neuroscience, Newcastle University) for assistance with the immunohistochemistry; and Hannah Rosa for the staining with the Rockland antibody.

The authors declare no competing financial interests.

This article is freely available online through the J Neurosci Author Open Choice option.

Correspondence should be addressed to Dr. Gabriele Saretzki, Newcastle University Institute for Ageing, Campus

for Ageing and Vitality, Edwardson Building, Newcastle University, Newcastle upon Tyne, NE4 5PL, UK. E-mail: gabriele.saretzki@newcastle.ac.uk.

DOI:10.1523/JNEUROSCI.2925-14.2015

Copyright $\odot 2015$ Spilsbury et al.

This is an Open Access article distributed under the terms of the Creative Commons Attribution License (http://creativecommons.org/licenses/by/3.0), which permits unrestricted use, distribution and reproduction in any medium provided that the original work is properly attributed. mitochondria, which provide sufficient energy to maintain synaptic activity (Wong-Riley, 1989; Attwell and Laughlin, 2001). However, mitochondrial function declines with age and can be impaired in neurodegenerative diseases (Shigenaga et al., 1994; Beal, 2005; Eckert et al., 2010). Dysfunctional mitochondria contribute to oxidative stress, through generation of ROS, which have been linked to brain aging and neurodegeneration (Barnham et al., 2004; Lin and Beal, 2006; Chou et al., 2011).

Telomerase is a reverse transcriptase best known for its telomere maintenance function in dividing cells. This requires two subunits: the enzyme TERT (telomerase reverse transcriptase) and the RNA component TERC (telomerase RNA component). However, an extranuclear localization of TERT has been reported (Haendeler et al., 2003, 2009; Ahmed et al., 2008; Eitan et al., 2012a). In rodents, TERT expression is maintained into adulthood (Klapper et al., 2001; Lee et al., 2010); and although telomerase activity is confined to areas containing stem cells (Caporaso et al., 2003), nontelomeric functions of the TERT protein have been shown in adult neurons (Kang et al., 2004; Iannilli et al., 2013). However, there is little information regarding TERT expression in human brain tissue, aside from its strong upregulation in brain tumors (Shay and Bacchetti, 1997; Falchetti et al., 2002; Koelsche et al., 2013).

Prosurvival effects of telomerase have been demonstrated in rodent neurons following various insults, such as ischemia, amyloid peptides, and both glutamate and NMDA-induced neurotoxicity (Fu et al., 2000; Zhu et al., 2000; Klapper et al., 2001; Lu et al., 2001; Kang et al., 2004; Lee et al., 2008). Several in vitro studies 
Table 1. Age, gender, Braak stages, PMD, and use of brains in the study ${ }^{a}$

\begin{tabular}{|c|c|c|c|c|c|c|c|c|}
\hline Case no. & Thal $A \beta$ phase & Braak stage & CERAD & AD neuropathologic change & Age (yr) & Gender & PMD (h) & Analysis \\
\hline 1 & 0 & 0 & - & No & 68 & M & 54 & WB/IF/ELISA \\
\hline 2 & 1 & 0 & - & Low & 78 & $\mathrm{~F}$ & 34 & WB/IF/ELISA \\
\hline 3 & 0 & 0 & - & No & 73 & M & 25 & WB/IF/ELISA \\
\hline 4 & 0 & 0 & - & No & 63 & M & 30 & ELISA \\
\hline 5 & 1 & 0 & - & Low & 75 & M & 20 & ELISA \\
\hline 6 & 0 & 0 & - & No & 59 & $\mathrm{~F}$ & 19 & ELISA \\
\hline 7 & 1 & 1 & - & Low & 73 & $\mathrm{~F}$ & 16 & WB/IF/ELISA \\
\hline 8 & 1 & 1 & - & Low & 72 & M & 17 & ELISA \\
\hline 9 & 1 & 2 & $A$ & Low & 83 & $\mathrm{~F}$ & 19 & WB/IF/ELISA \\
\hline 10 & 1 & 2 & - & Low & 74 & $\mathrm{~F}$ & 45 & WB/IF/ELISA \\
\hline 11 & 2 & 2 & $A$ & Low & 87 & M & 8 & ELISA \\
\hline 12 & 1 & 2 & - & Low & 78 & $\mathrm{~F}$ & 23 & ELISA \\
\hline 13 & 0 & 3 & - & No & 88 & $\mathrm{~F}$ & 22 & WB/IF/ELISA \\
\hline 14 & 2 & 3 & - & Low & 89 & $\mathrm{~F}$ & 34 & WB/IF/ELISA \\
\hline 15 & 0 & 3 & - & No & 81 & M & 43 & WB/IF/ELISA \\
\hline 16 & 2 & 3 & A & Low & 84 & $\mathrm{~F}$ & 8 & ELISA \\
\hline 17 & 3 & 3 & A & Intermediate & 91 & M & 12 & ELISA \\
\hline 18 & 4 & 3 & C & Intermediate & 79 & M & 13 & ELISA \\
\hline 19 & 4 & 6 & $C$ & High & 83 & $\mathrm{~F}$ & 12 & WB/IF/ELISA \\
\hline 20 & 5 & 6 & $c$ & High & 86 & $\mathrm{~F}$ & 5 & WB/IF/ELISA \\
\hline 21 & 5 & 6 & $C$ & High & 76 & $\mathrm{~F}$ & 37 & WB/IF/ELISA \\
\hline 22 & 4 & 6 & C & High & 72 & $\mathrm{~F}$ & 27 & ELISA \\
\hline 23 & 5 & 6 & B & High & 77 & $\mathrm{~F}$ & 30 & ELISA \\
\hline 24 & 4 & 6 & $C$ & High & 59 & M & 44 & ELISA \\
\hline
\end{tabular}

aPMD, Postmortem delay; WB, Western blotting; IF, immunofluorescence.

have demonstrated the ability of TERT to shuttle from the nucleus to mitochondria upon oxidative stress, where it decreases levels of ROS, DNA damage, and apoptosis, and improves mitochondrial membrane potential, respiration, and complex I activity (Ahmed et al., 2008; Haendeler et al., 2009; Singhapol et al., 2013).

In this study, we investigated the ability of TERT to protect against tau pathology. We demonstrate that TERT protein is expressed in adult human hippocampal neurons. We show that TERT localizes to mitochondria upon oxidative stress in cultivated neurons and in the hippocampal neurons of $\mathrm{AD}$ brains. Additionally, there is a mutual exclusion of TERT and NFT/NT. Neurons lacking TERT display an increased production of oxidative species and an increase in cellular oxidative damage in response to tau. Together, our results suggest that TERT protects hippocampal neurons against oxidative stress induced by pathological tau.

\section{Materials and Methods}

All chemicals were from Sigma, and all culture media from Invitrogen unless otherwise stated.

Human hippocampal tissue. Our study used 24 postmortem brains: 6 age-matched controls without tau pathology, 12 with Braak stages ranging from I to III and 6 with AD (Braak Stage VI) (Braak and Braak, 1991; Braak et al., 2006) (Table 1). Brain tissue was collected by the Newcastle Brain Tissue Resource at Newcastle University, United Kingdom, after relevant informed consent from donors and in accordance with Newcastle University ethics board and ethical approval awarded by the Joint Ethics Committee of Newcastle and North Tyneside Health Authority (reference 08/H0906/136). All brains were assessed neuropathologically according to published criteria (Mirra et al., 1991; Thal et al., 2002; Braak et al., 2006; Montine et al., 2012) and were free of non-AD pathology in the hippocampus (e.g., Lewy body pathology, TDP-43 inclusions, hippocampal sclerosis).

Mice. TERT knock-out mice (TERT ${ }^{-/-}$) (Chiang et al., 2004) were obtained from The Jackson Laboratory and had the genotype B6.129STert, tm1Yjc/J. Heterozygous mice were bred to obtain wild-type and first generation (G1) homozygous knock-out mice. Ethical approval was granted by the Local Research Ethics Committee, Newcastle University, UK. The work was licensed by the UK Home Office (PPL 60/3864) and complied with the guiding principles for the care and use of laboratory animals in the United Kingdom. The housing and use of mice were according to local guidelines and governed by the UK Animals (Scientific Procedures) Act 1986. Animals were housed in conventional clean facility in North Kent Plastic M2 cages in the same room and provided with sawdust, paper bedding, and had ad libitum access to water and food. The diet used was standard rodent chow (CRM (P), Special Diets Services). Mice were housed at $20 \pm 2^{\circ} \mathrm{C}$ under a $12 \mathrm{~h}$ light $/ 12 \mathrm{~h}$ dark photoperiod. The dams and embryos were killed by a schedule 1 method.

Lentiviral constructs. Full-length human T40 tau in pET29b(+) was obtained from Addgene (Peter Klein (Hedgepeth et al., 1997), Addgene plasmid 16316, Cambridge), and the tau gene was cut from the vector using EcoRI and XbaI. Following restriction digest, the gene was truncated at aa151-391 by PCR with primers designed by Zilkova et al. (2011). Truncated tau was ligated into pENTR2B (Invitrogen). Mutated P301L tau (2N4R) in pENTR/SD/TOPO was kindly provided by Prof. Juergen Goetz (University of Queensland, Brisbane, Australia). The truncated tau and P301L tau genes were transferred to pLenti6/V5-DEST vectors (Invitrogen), using LR Clonase II, according to the manufacturer's guidelines (Invitrogen). Gene inserts were sequenced (GATC Biotech) to verify correct orientation and absence of any nucleotide mutations.

Immunofluorescent staining of human hippocampal tissue. Immunofluorescent staining of human hippocampal sections was conducted. Sections $(10 \mu \mathrm{M})$ were deparaffinized in Histo-Clear (National Diagnostics) and rehydrated in decreasing concentrations of methanol. Antigen retrieval was performed in $0.01 \mathrm{M}$ citrate buffer with $0.005 \%$ Tween 20 by microwaving at full power $(800 \mathrm{~W})$ for $4 \mathrm{~min}$, and at $40 \%$ power for a further $10 \mathrm{~min}$. Sections were treated with $70 \%$ formic acid for $10 \mathrm{~min}$, followed by Sudan black $(0.5 \% \mathrm{w} / \mathrm{v}$ in $70 \%$ ethanol) for a further $30 \mathrm{~min}$ to reduce lipofuscin autofluorescence. Sections were blocked in PBS containing $10 \%$ normal goat serum (NGS) and $0.1 \%$ BSA at room temperature for $60 \mathrm{~min}$. Sections were incubated in a humidified chamber overnight at $4^{\circ} \mathrm{C}$ with primary antibodies (Table 2) in PBS containing 2\% NGS and $0.1 \%$ BSA. Negative controls where the primary antibody was omitted were included in all experiments (see Fig. $1 A$, right, top row). Appropriate AlexaFluor-conjugated secondary antibodies (Invitrogen) 
Table 2. Information on the primary antibodies used in the study ${ }^{a}$

\begin{tabular}{llll}
\hline Antibody & Dilution & Manufacturer & Catalog no. \\
\hline Anti-TERT & IF, 1:100; WB, 1:500 & Abcam & ab32020 \\
Anti-TERT & IF, 1:200 & Rockland & $600-401-2525$ \\
Anti-AT8 (PHF-tau (Ser202/Thr205) & IF, 1:1000 & Thermo & MN1020 \\
Anti-MTC01 & IF, 1:500; WB, 1:2000 & Abcam & ab14705 \\
Anti-VDAC/porin & IF, 1:200; WB, 1:1000 & Abcam & ab16816 \\
Anti-GFAP (mouse) & IF, 1:100 & Abcam & ab10062 \\
Anti-CD68 (clone PG-M1) & IF, 1:100 & Dako & NA \\
Anti- $\gamma H 2 A X$ & IF, 1:250 & Cell signaling & \#9718 \\
Anti- $\beta$ III-tubulin & IF, 1:1000; WB, 1:1000 & Abcam & ab18207 \\
Anti-GFAP (rabbit) & IF, $1: 1000$ & Dako & NA \\
Anti-4 hydroxynonenal & IF, 1:500 & Abcam & ab46545 \\
Anti-calnexin & IF, 1:100 & Sigma & C7617 \\
Anti-AIF & WB, 1:1000 & Abcam & ab32516 \\
Anti-T0MM20 & WB, 1:1000 & Abcam & ab56783 \\
Anti-MnS0D & WB, 1:1000 & Millipore & $06-984$ \\
Anti-NDUFA9 & WB, 1:1000 & Abcam & ab14713 \\
\hline
\end{tabular}

${ }^{a} \mathrm{~F}, \mathrm{Immunofluorescence;} \mathrm{WB}$, Western blotting; NA, not applicable.

were applied for $60 \mathrm{~min}$. When used, NeuroTrace (1:150, Invitrogen) in PBS was applied for $20 \mathrm{~min}$ at room temperature before counterstaining with DAPI. Sections were stained with DAPI (Cystain UV Ploidy, Partec) for $15 \mathrm{~min}$ and coverslips (Agar Scientific, VWR) were mounted using Vectashield anti-fade mounting solution (Vector Laboratories). Images were acquired using fluorescence microscopy (Leica DM5500B, Leica Microsystems; Axio Observer.Z1, Zeiss) or confocal microscopy (Zeiss Observer Z1, Quant EM 512SC camera, with Yokogawa CSU-X1 spinning-disk). Individual neurons were outlined and fluorescence intensity measured and taken as average pixel intensity over the total area. The background value was then subtracted. To measure colocalization between TERT and mitochondria, images were analyzed using the JaCoP plug-in for ImageJ. Briefly, images ( $z$-stacks) were thresholded and analyzed for spatial colocalization using the Pearson's correlation coefficient ( 0 , no colocalization; 1 , total colocalization; $x$-, $y$-, $z$-block sizes were $2 \mathrm{px})$. Subsequently, Costes' method was used to create randomized images of the TERT channel (50 randomization rounds per $z$-stack slice, bin width of 0.001 ), which were compared with the mitochondrial channel, from which a second Pearson's correlation coefficient was calculated. This value was then compared with the original colocalization calculation. Resulting $p$ values $>95 \%$ indicated that colocalization in the original image was not through random chance. Statistical analysis was performed using one-way ANOVA with Tukey's post hoc test.

Western blotting. Total protein was extracted from frozen human hippocampal tissue or primary neurons in a lysis buffer containing $50 \mathrm{~mm}$ Tris base, $\mathrm{pH} 7.5,150 \mathrm{~mm} \mathrm{NaCl}, 1 \%$ Triton X-100, and Halt Protease Inhibitor Cocktail 100× (Thermo Fisher). Denatured samples (100 $\mu \mathrm{g} /$ lane) were run on $8 \%$ SDS-polyacrylamide gels alongside molecular weight markers (MW 10,000-250,000; PageRuler Plus, Thermo Fisher) and transferred to nitrocellulose membranes by wet electroblotting. Membranes were blocked in TTBS containing 5\% (w/v) skimmed milk powder (Marvel) for $1 \mathrm{~h}$ at room temperature and incubated with primary antibodies (Table 2) overnight at $4^{\circ} \mathrm{C}$ in TTBS/milk. Blots were incubated with HRP-conjugated secondary antibodies (1:1000; Abcam) in TTBS/milk for $1 \mathrm{~h}$. Finally, the blots were exposed to ECL Plus/Prime reagent (GE Healthcare) and placed in an ImageQuant LAS-4000 chemiluminescent detector (GE Healthcare). Relative band intensities were obtained by densitometric analysis of images using ImageJ. Background signal was subtracted from each band; the values were normalized to the loading control $\beta$ III-tubulin and expressed as mean \pm SEM. Data were analyzed using one-way ANOVA.

Mitochondrial subfractionation. Mitochondria were isolated from mouse liver, as described previously (Miwa et al., 2014). Briefly, mouse liver was chopped and rinsed in ice-cold isolation medium $(250 \mathrm{~mm}$

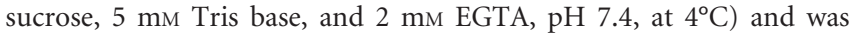
homogenized by a glass homogenizer (Wheaton $15 \mathrm{ml}$ Dounce tissue grinder) using six strokes with a loose-fit pestle and centrifuged at $1050 \times$ $g$ for $3 \mathrm{~min}$. The supernatant was centrifuged at $11,630 \times g$ for $10 \mathrm{~min}$, and the pellet was washed two more times in isolation medium. The resultant pellet was resuspended in $0.5 \mathrm{ml}$ of isolation medium (crude mitochondria) followed by purification by Percoll density centrifugation

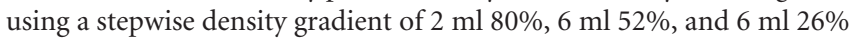
Percoll in isolation medium, at $41,100 \times g$ for $45 \mathrm{~min}$. The mitochondria were collected from the $26 \% / 52 \%$ interface and washed twice with isolation medium at $11,600 \times g$ to obtain the purified mitochondria. An aliquot of each liver homogenate and of pure mitochondria was snap frozen in liquid $\mathrm{N}_{2}$.

To obtain mitoplasts, $1 \mathrm{ml}$ of $10 \mathrm{~mm}$ Tris/ $\mathrm{HCl}$ at $\mathrm{pH} 7.4$ was added to $1 \mathrm{mg}$ of pure mitochondria and the sample divided into two aliquots of $500 \mu \mathrm{l}$ each. To obtain proteinase K-shaved mitoplasts, proteinase K (2.7 $\mu \mathrm{g}$ ) was added to one aliquot of mitoplasts at a final concentration of 5.4 $\mathrm{ng} / \mu \mathrm{l}$ and incubated for $30 \mathrm{~min}$ on ice. The reaction was stopped by adding $5 \mathrm{mM}$ PMSF. An equal volume of $2 \times$ STE buffer was added to both aliquots, and they were centrifuged at $12,000 \times g$ for $10 \mathrm{~min}$ at $4^{\circ} \mathrm{C}$. The pellets were resuspended in $60 \mu \mathrm{l} \mathrm{STE}$. The aliquot of nonshaved mitoplasts was snap frozen in liquid $\mathrm{N}_{2}$. The shaved mitoplasts were divided into two aliquots of $30 \mu \mathrm{l}$ : one was snap frozen (mitoplast + Proteinase K) and to the other $970 \mu \mathrm{l}$ of STE was added and the sample centrifuged at $12,000 \times \mathrm{g}$ for $10 \mathrm{~min}$ at $4^{\circ} \mathrm{C}$. To the pellet, $2.7 \mathrm{ml}$ of 100 $\mathrm{mm} \mathrm{NaCO}$ was added and incubated for $30 \mathrm{~min}$ on ice. The sample was centrifuged at $100,000 \times g$ for $15 \mathrm{~min}$ at $4^{\circ} \mathrm{C}$ to obtain a pellet containing the inner membrane fraction, which was resuspended in $30 \mu \mathrm{l} \mathrm{STE}$ and snap frozen in liquid $\mathrm{N}_{2}$.

TERT ELISA. TERT ELISA (GenWay) was performed according to the manufacturer's guidelines. Frozen hippocampal tissue lysates were prepared using the identical method as for Western blotting. TERT ELISA (GenWay) was performed using $100 \mu \mathrm{g}$ of total protein per sample, each run in duplicate. Plates were read in a microplate reader at a wavelength of $450 \mathrm{~nm}$ (FLUOstar Omega, BMG Labtech). Standards of recombinant TERT protein at concentrations between 50 and $3.125 \mu \mathrm{g}$ were run in duplicate, from which a linear regression curve was drawn with an $r^{2}$ value of 0.996 . From this graph, the amount of TERT in each sample was calculated. Data were analyzed using one-way ANOVA.

Telomerase activity measurements using TRAP ELISA. Measurement of telomerase activity in cultivated neurons was performed using the TeloTAGGG Telomerase PCR ELISA (Roche), according to the manufacturer's guidelines. Total protein was extracted from neurons at 3-14 DIV using CHAPS buffer, protein quantified using Bradford reagent, and 500 ng of protein was used for each sample. PCR was run at 30 cycles and the ELISA measured at $450 \mathrm{~nm}$ on a plate reader (FLUOstar Omega, BMG Labtech). Values of $\leq 0.2$ are considered negative according to the manufacturer's guidelines.

Primary astrocyte and neuronal culture. For the generation of embryos, wild-type mice and first generation TERT ${ }^{-1-}$ mice were timed mated. Primary cultures were prepared from 16-day-old embryos of either sex, using methods described previously (Spilsbury et al., 2012). Astrocytes were cultivated as described previously (Spilsbury et al., 2012). Neuronal cultures were seeded at a density of $1 \times 10^{6} \mathrm{cells} / \mathrm{ml}$ on culture dishes that had been coated previously with $15 \mu \mathrm{g} / \mathrm{ml}$ poly-L-ornithine overnight, subsequently washed, and then coated with $5 \mu \mathrm{g} / \mathrm{ml}$ laminin. Neurons were maintained in Neurobasal medium supplemented with $2 \%$ B27, 0.5 $\mathrm{mm}$ mL-glutamine, and $100 \mathrm{U} / \mathrm{ml}$ penicillin/100 $\mu \mathrm{g} / \mathrm{ml}$ streptomycin (all from Invitrogen). After 4-5 DIV, $5 \mu \mathrm{M}$ arabinofuranosyl cytidine was added to the culture media to limit proliferation of glial cells. All primary cells were cultured at $37^{\circ} \mathrm{C}$ in a humidified atmosphere of $5 \% \mathrm{CO}_{2}$ and $3 \% \mathrm{O}_{2}$. Neurons were transduced at $8 \mathrm{DIV}$ and analyzed after $11 \mathrm{DIV}$, when the majority of cells were neuronal, as verified by $\beta$ III-tubulin and GFAP immunofluorescence and had lost telomerase activity.

Lentiviral transductions. Lentiviral transductions were performed according to the manufacturer's guidelines (Invitrogen), with slight modifications. HEK293FT cells were transfected with truncated or mutated tau using Lipofectamine 2000 (Invitrogen). Viruses were harvested in Neurobasal medium $\sim 48 \mathrm{~h}$ after transfection. Neurons were incubated with viral particles for $\sim 72 \mathrm{~h}$ in a hypoxic incubator, before replacing the growth media or fixing. The optimal transduction efficiency was determined by using an mCherry reporter lentivirus and through immunofluorescent labeling with an AT8 antibody, which specifically recognized 
transduced neurons (see Fig. $7 A$, left images). Untransduced neurons were not labeled with the AT8 antibody (see Fig. 7A, right images).

Immunofluorescence: cell cultures. Astrocytes or neurons grown on 19 mm glass coverslips (VWR) were fixed at 12 DIV and between 11 and 18 DIV, respectively, using 4\% PFA for $10 \mathrm{~min}$. They were subsequently blocked and permeabilized in PBS containing 1\% NGS and $0.2 \%$ Triton $\mathrm{X}-100$ for $30 \mathrm{~min}$. Coverslips were incubated with primary antibodies (Table 2) in PBS containing $1 \%$ NGS overnight at $4^{\circ} \mathrm{C}$. AlexaFluor secondary antibodies (1:1000; Invitrogen) were added in PBS/NGS for 60 min. DAPI was applied for $10 \mathrm{~min}$, and the coverslips were mounted onto microscope slides using Vectashield. Images were acquired using fluorescence microscopy or confocal microscopy. To measure colocalization, images were deconvolved using the 3D Huygens Deconvolution \& Analysis Software (Scientific Volume Imaging), and Pearson's correlation coefficients were calculated. Statistical analysis was performed using oneway ANOVA with Tukey's post hoc test.

Measurement of superoxide in cultured neurons. Superoxide was measured in neurons on 96-well plates, after treatment with hydrogen peroxide (75 $\mu \mathrm{M}, 1 \mathrm{U} / \mathrm{ml}$ glucose oxidase; $1 \mathrm{~h}$ ). Neurons were incubated in serum-free medium containing dihydroethidium (DHE; $1.25 \mu \mathrm{M}, 30$ min at $\left.37^{\circ} \mathrm{C}\right)$ using Hoechst $33342(1 \mu \mathrm{g} / \mathrm{ml})$ to normalize for cell number (both Invitrogen). Subsequently, the medium was changed and plates read in a microplate reader (FLUOstar Omega, BMG Labtech) at wavelengths of 355/460 nm (Hoechst) and 544/590 nm (DHE). Background fluorescence was subtracted from both measurements and the values expressed as a ratio of DHE/Hoechst.

Measurement of mitochondrial superoxide and lipid peroxidation in cultured neurons. Following transduction with truncated and mutated tau, mitochondrial superoxide was measured using the MitoSOX probe (Invitrogen). Neurons were incubated with MitoSOX $(5 \mu \mathrm{M}, 15 \mathrm{~min}$ at $37^{\circ} \mathrm{C}$ ) in Neurobasal medium before fixation with $4 \%$ PFA and immunolabeling with anti-AT8 antibody and counterstaining with DAPI. MitoSOX fluorescence was imaged by confocal microscopy at wavelengths of 540/560 nm. For measurement of lipid peroxidation, neurons were immunolabeled with an anti-4-HNE antibody, alongside anti-AT8 antibody and nuclear counterstain. For fluorescent measurements, individual neurons were selected using the AT8 channel and imaged through $z$-stacks. The soma was defined as the area immediately surrounding the nucleus. The microtubules of dendrites were labeled with AT8. Apical dendrites were identified as the thickest primary processes extending from the apex of the soma, basal dendrites the thinner primary, and secondary processes opposing the apical dendrite. Multiple line profiles were taken for each subcellular region, and the average pixel intensity was calculated.

\section{Results}

TERT expression in human hippocampus, and in cultured neurons and glial cells

To date, the expression of TERT protein in adult human brain has not been described. To examine which cells within human brain tissue express TERT protein, we performed immunolabeling of hTERT protein in hippocampal sections from aged individuals. The anti-TERT monoclonal antibody used in this study (ab32020, Abcam) has been validated for specificity by us (Fig. $1 B$, bottom, $D$ ) and by others (Eitan et al., 2012b; Xi et al., 2013; Zaug et al., 2013), and a single amino-acid substitution in the C-terminal epitope of hTERT has been shown to abolish the signal (Zaug et al., 2013). Immunostaining revealed TERT protein in hippocampal neurons (Fig. $1 A$, top two rows). TERT fluorescence was found in the cytoplasm throughout the soma and dendrites. However, there was not a considerable amount of nuclear staining. TERT staining in human neurons was also verified using an hTERT antibody from Rockland (Fig. 1C). When sections were costained with TERT and GFAP, GFAP-positive astrocytes did not express TERT (Fig. 1A, bottom row). However, TERT was expressed in activated microglia labeled with CD68 (Fig. 1A, third row).
We also examined TERT expression in vitro in cultured mouse brain cells. We derived neuronal and glial cultures from embryonic mouse cortex and identified which of the cell types expressed TERT protein in vitro. In primary neuronal cultures double immunolabeled with $\beta$ III-tubulin and TERT, we observed TERT protein in the cytoplasm of the soma and dendrites (Fig. $1 B$, top row). In mixed glial cultures (14 DIV), we found an intense labeling of activated microglia, which were identified using a CD68 antibody (Fig. $1 B$, second row), whereas astrocytes labeled with GFAP displayed a small amount of fluorescence in the cytoplasm (Fig. $1 B$, third row). The latter observation is most likely due to the fact that cultured astrocytes express telomerase initially and that it is quickly downregulated on reaching confluence. Using a TRAP ELISA, we also measured telomerase activity in neurons at 3-14 DIV. We found a strong reduction in telomerase activity of neurons $\sim 11 \mathrm{~d}$ in culture (Fig. $1 E$ ) corresponding to earlier observations (Fu et al., 2002a).

It has been shown that there is a reduction in expression of TERT protein in brain in a model of neurodegenerative disease (amyotrophic lateral sclerosis [ALS]), and in Purkinje neurons during normal aging in mice (Eitan et al., 2012a, 2012b). However, it is currently unknown whether this also occurs during human aging and in neurodegenerative disease. Therefore, we measured TERT protein expression in the hippocampus during progression of $\mathrm{AD}$ pathology as reflected by Braak stages, using three independent methods. Because TERT is known to have protective noncanonical functions in vitro ( $\mathrm{Fu}$ et al., 2000; Ahmed et al., 2008; Haendeler et al., 2009; Sharma et al., 2012; Saretzki, 2014) and in vivo (Kang et al., 2004; Lee et al., 2008; Eitan et al., 2012b), we hypothesized that a decrease in TERT protein may play a role in neuronal susceptibility to tau pathology. We chose to investigate the relationship between TERT and hyperphosphorylated tau specifically because tau, like TERT, is predominantly intracellular where it occurs in cellular somata in the form of neurofibrillary tangles and in neuronal processes as neuropil threads (Alonso et al., 1996; Duyckaerts et al., 2009). Moreover, tau is the more prevalent $\mathrm{AD}$ pathology in the hippocampus. Tau may be also be present extracellularly in the form of so-called "ghost tangles," where the tangle-bearing neurons have died off and only the tangles remain (Cras et al., 1995). In addition, TERT and tau have both been shown to interact with mitochondrial proteins, having opposite effects on the activity of complex I of the electron transport chain (Haendeler et al., 2009; Rhein et al., 2009).

We performed Western blotting detecting TERT in protein lysates from hippocampal tissue of healthy age-matched control cases (Braak Stage 0), from cases with low Braak stages (I-III), and from AD cases (i.e., Braak Stage VI). We chose to include low Braak stage cases to examine whether there was a relationship between the amount of hippocampal tau pathology and the levels of TERT expression. The anti-TERT antibody detected clear bands of the correct size. Bands were quantified and normalized to neuronal $\beta$ III-tubulin and revealed that TERT expression did not differ between controls and cases with Braak Stage I-VI (Fig. $2 A)$. To corroborate our findings, a sandwich ELISA detecting TERT protein was used to measure TERT expression in controls and from each of these Braak stages: I/II, III, and VI (Fig. 2B). Results from these experiments were in agreement with the Western blotting data indicating no change in total TERT expression between controls and the different Braak stages.

Because lysates used in Western blots and TERT ELISA contained total protein from all hippocampal cell types, we used immunofluorescence to enable a more sensitive measurement of 
A
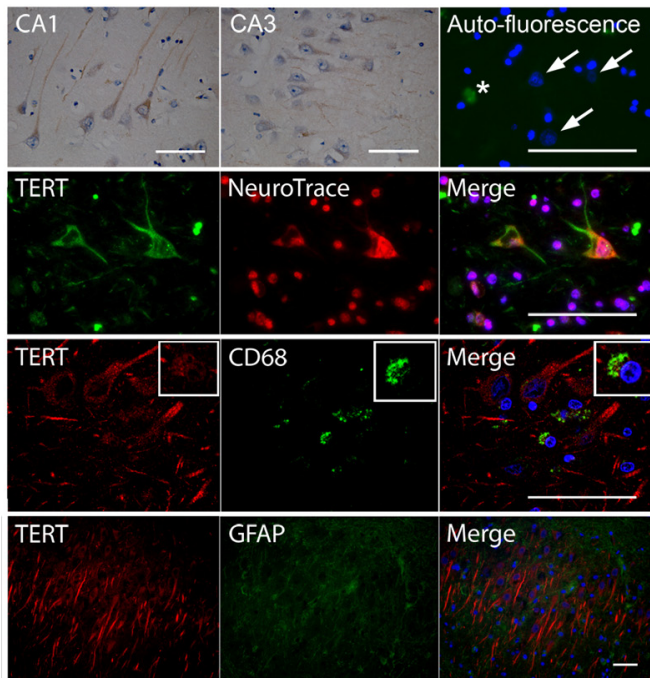

C TERT (Rockland)

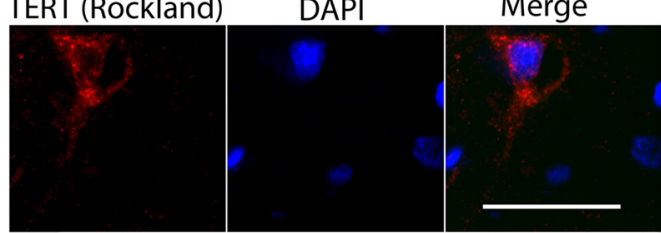

D

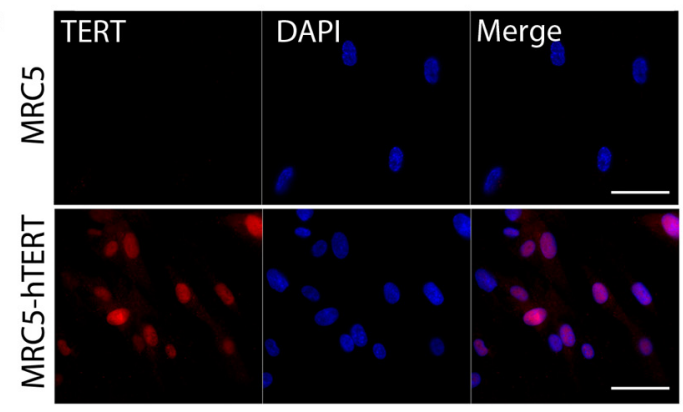

B
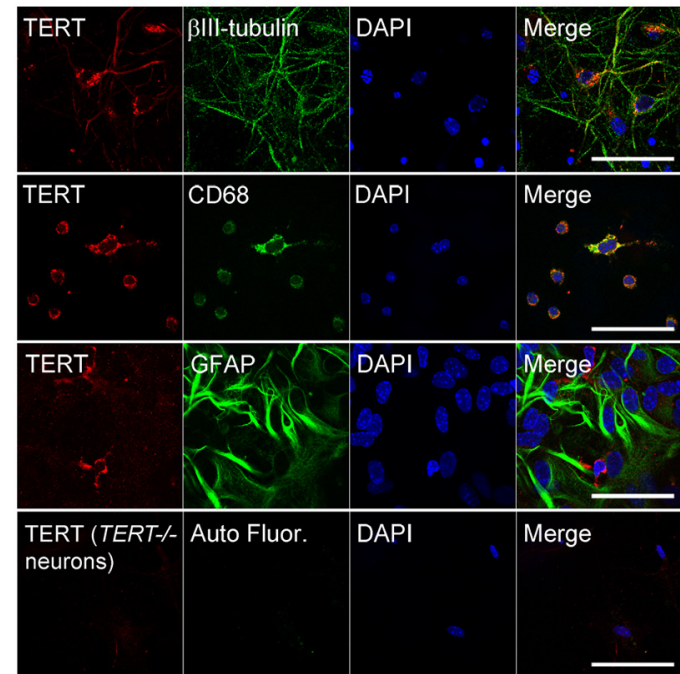

$\mathbf{E}$

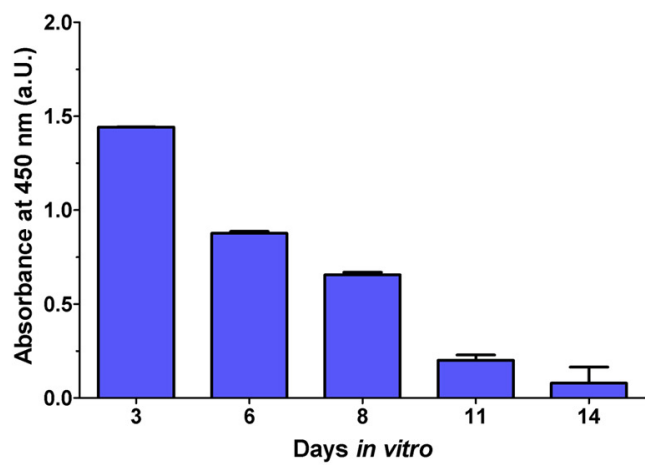

Figure 1. Expression of TERT in human hippocampus and in cultured neurons and glia. $A$, Images showing immunohistochemical and immunofluorescent labeling of TERT in human hippocampus. Top, TERT (brown) and hematoxylin (blue) labeled neurons in the CA1 and CA3 regions of the hippocampus. Right, Immunofluorescence image shows secondary antibody only control (green). Arrows indicate neuronal nuclei. * Autofluorescence of a blood vessel. Second panel, TERT (green) is detected in the cytoplasm of neurons, which are identified using the neuronal marker NeuroTrace (red) and nuclear counterstain (DAPl; blue). Third panel, TERT (red) is expressed by microglial cells, as determined using antibodies against the microglial marker, CD68 (green). Bottom, TERT (red) specific staining was absent in astrocytes, as determined by double-labeling with astrocyte marker, GFAP (green). $\boldsymbol{B}$, Images showing immunofluorescent labeling of TERT (red) in cultured embryonic mouse neurons and glia. The cell-specific markers $\beta$ III-tubulin, CD68, and GFAP identify neurons, microglia, and astrocytes, respectively (green). Top, Neurons express TERT protein in the cytoplasm of the soma and dendrites, but not in the nucleus. Second panel, Activated microglia show high expression of TERT protein in the cytoplasm. Third panel, Astrocytes in culture do not show fluorescent staining of TERT protein. Bottom, Neurons derived from TERT ${ }^{-1-}$ mice do not label with the anti-TERT antibody. C, An additional antibody recognizing TERT (Rockland) also labels the cytoplasm of human neurons. D, TERT antibody (Abcam) specificity is demonstrated in MRC5 and MRC5-hTERT overexpressing fibroblasts. Top, MRC5 fibroblasts show an absence of TERT staining. Bottom, Intense labeling of TERT (red) in the nucleus of MRC5-hTERT overexpressing fibroblasts. E, Telomerase activity is downregulated in embryonic mouse neurons in culture. Data are mean \pm SEM. Scale bars, $50 \mu \mathrm{m}$.

neuronal TERT expression. Using immunofluorescent staining, we labeled hippocampal sections with TERT and NeuroTrace, a neuron-specific fluorescent Nissl stain (Fig. 2D), and TERT expression was quantified in hippocampal sectors CA1, CA2, CA3, CA4, and DG (granule cell layer). However, these measurements also indicated that TERT expression in individual neurons is unchanged between controls and Braak Stage I-VI cases, regardless of the hippocampal region (Fig. 2C).

Together, these data suggest that there does not seem to be a change in TERT protein levels in hippocampal neurons in the early and intermediate Braak stages of tau pathology or in AD.

TERT colocalizes with mitochondria in advanced AD pathology

It has been shown, that under conditions of oxidative stress, TERT shuttles to the mitochondria, where it reduces ROS pro- duction, increases mitochondrial membrane potential, and improves respiratory chain function (Ahmed et al., 2008; Haendeler et al., 2009; Singhapol et al., 2013). Because we saw no differences in TERT protein levels in hippocampus at any Braak stage, we hypothesized that TERT may undergo a shift in subcellular localization to the mitochondria in neurons upon $\mathrm{AD}$ pathology. To investigate this, double immunofluorescent labeling of MTCO1 (COX1 protein from complex IV of the electron transport chain) and TERT was performed (Fig. $3 A-C$ ), and colocalization determined between the two proteins. Pearson's correlation analysis showed a significant increase in the proportion of colocalization between TERT and mitochondria in surviving hippocampal neurons in CA1 $(128 \pm 11.9 \%, p=0.021)$, CA2 $(107 \pm 10.3 \%, p=$ $0.002)$, and CA3 $(74 \pm 9.9 \%, p=0.029)$ in $\mathrm{AD}$ (i.e., Braak Stage VI) compared with controls (Fig. 3D). However, we found no significant differences in the CA4 or DG regions, or between 
A
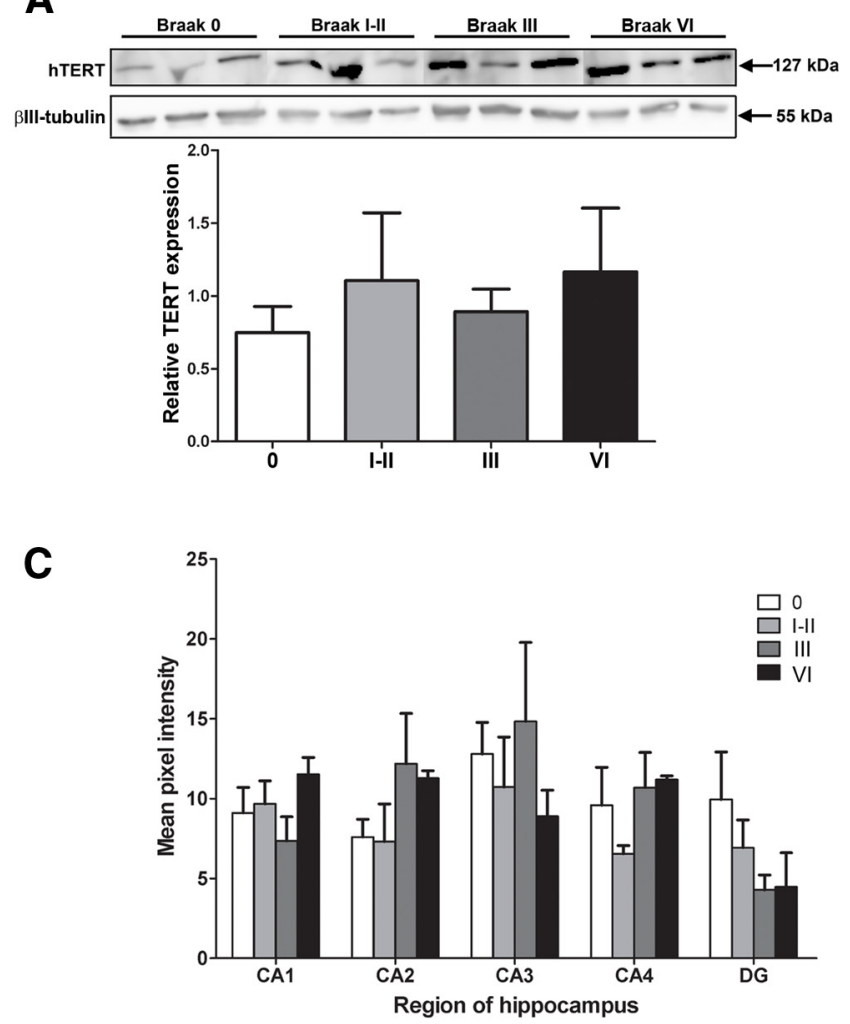

B

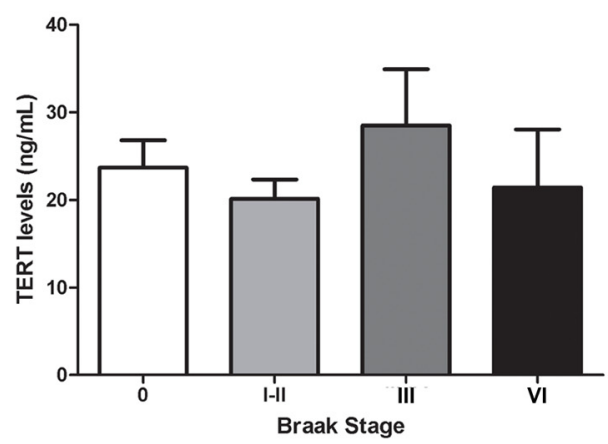

D

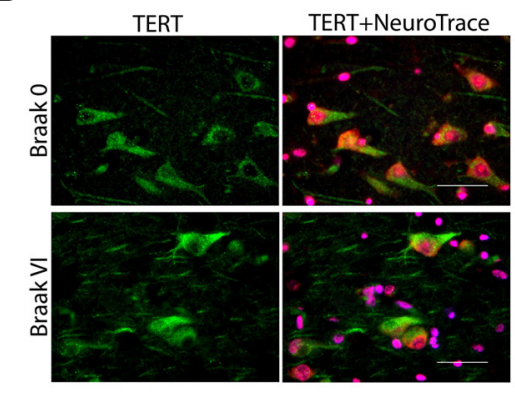

Figure 2. Expression of TERT protein in the hippocampus at different Braak stages. A, Appropriately sized bands represent hTERT protein (127 kDa) and $\beta \| \mathrm{II}-$ tubulin ( $55 \mathrm{kDa}$ ) as a loading control. Graph represents densitometric analysis of relative band densities for hTERT protein. Data are mean \pm SEM for 3 cases per group, analyzed using one-way ANOVA. $\boldsymbol{B}$, Graph represents levels of $h$ TERT protein determined using a TERT ELISA. Data are mean \pm SEM from 6 cases per group, analyzed using one-way ANOVA. C, Hippocampal sections from age-matched controls, and from three AD groups, Braak I-II, III, and VI, were labeled with anti-TERT antibody (green) and a fluorescent Niss stain (NeuroTrace; red). Graph represents quantification of TERT immunofluorescence in neurons from five different areas of the hippocampus: CA1, CA2, CA3, CA4, and DG. Data are mean \pm SEM from 3 cases per group, analyzed using one-way ANOVA. $D$, Two representative fluorescence microscopy images show TERT and NeuroTrace-labeled neurons in the CA1 of a control donor and a Braak Stage VI donor. Scale bars, $50 \mu \mathrm{m}$.

controls (Braak Stage 0) and cases with intermediate Braak stages (I-III). The lack of an increase in colocalization in the CA4 or DG regions at Braak Stage VI could be due to these regions being less severely affected by tau pathology than the CA1, CA2, and CA3 regions (Lace et al., 2009).

To exclude that the increased TERT colocalization with mitochondria in $\mathrm{AD}$ cases is due to advanced Braak stages having a higher mitochondrial content, the latter was analyzed. Using Western blotting, we measured the expression of two mitochondrial proteins in lysates from AD cases (i.e., Braak Stage VI) and controls. However, there were no significant differences in levels of VDAC/porin or MTCO1 protein (Fig. 4A). To confirm this result, immunolabeling of hippocampal sections with MTCO1 was performed, and fluorescence measured in neurons of the CA1, CA2, CA3, and CA4. There were no significant differences in MTCO1 fluorescence intensity between controls and Braak Stage VI AD cases (Fig. 4B). This is in agreement with previous findings (Wang et al., 2009). Nevertheless, it is possible that activity of the respiratory complexes may be altered in neurons of the AD brain (Mutisya et al., 1994; Maurer et al., 2000).

\section{TERT protein is present in mouse liver mitochondrial} subfractions

To demonstrate localization of TERT within mitochondria, we isolated pure mitochondria from wild-type mouse liver and subfractionated them giving rise to mitoplast, proteinase K-shaved mitoplast, and inner membrane fractions. Western blotting revealed that TERT was enriched in mitochondria compared with whole liver lysate (Fig. 4C). In addition, bands specific to TERT were observed in the mitoplast, proteinase K-shaved mitoplast, and inner membrane fractions.

\section{Mutual exclusion of TERT and pathological tau in AD}

Considering the known protective functions of TERT in other cell systems, we hypothesized that TERT-expressing neurons could be more resistant to tau pathology. To determine whether TERT and pathological tau are present together in the same neurons, double immunofluorescent labeling was performed with antibodies recognizing TERT and hyperphosphorylated tau. Sections from cases with Braak Stage 0 and with Braak Stages III-VI were analyzed for TERT and AT8. As expected, in cases at Braak Stage 0, TERT staining was apparent in the neuronal cytoplasm, and no AT8 immunoreactivity was seen (Fig. 5, top row). In the sections of Braak Stages III-VI, AT8 immunoreactivity was found both as neuropil threads in neuronal cell processes and neurofibrillary tangles in neuronal somata. Interestingly, we did not find any overlapping of the TERT and AT8 signals, suggesting that TERT expression and the presence of tau pathology are mutually exclusive in neurons of the hippocampus (Fig. 5, bottom two rows).

\section{Neurons lacking TERT have increased susceptibility to oxidative stress}

Hydrogen peroxide increases mitochondrial superoxide in TERT ${ }^{-1-}$ neurons

It has been shown previously that knocking down TERT in cultured neurons resulted in increased susceptibility to oxidative stress and 

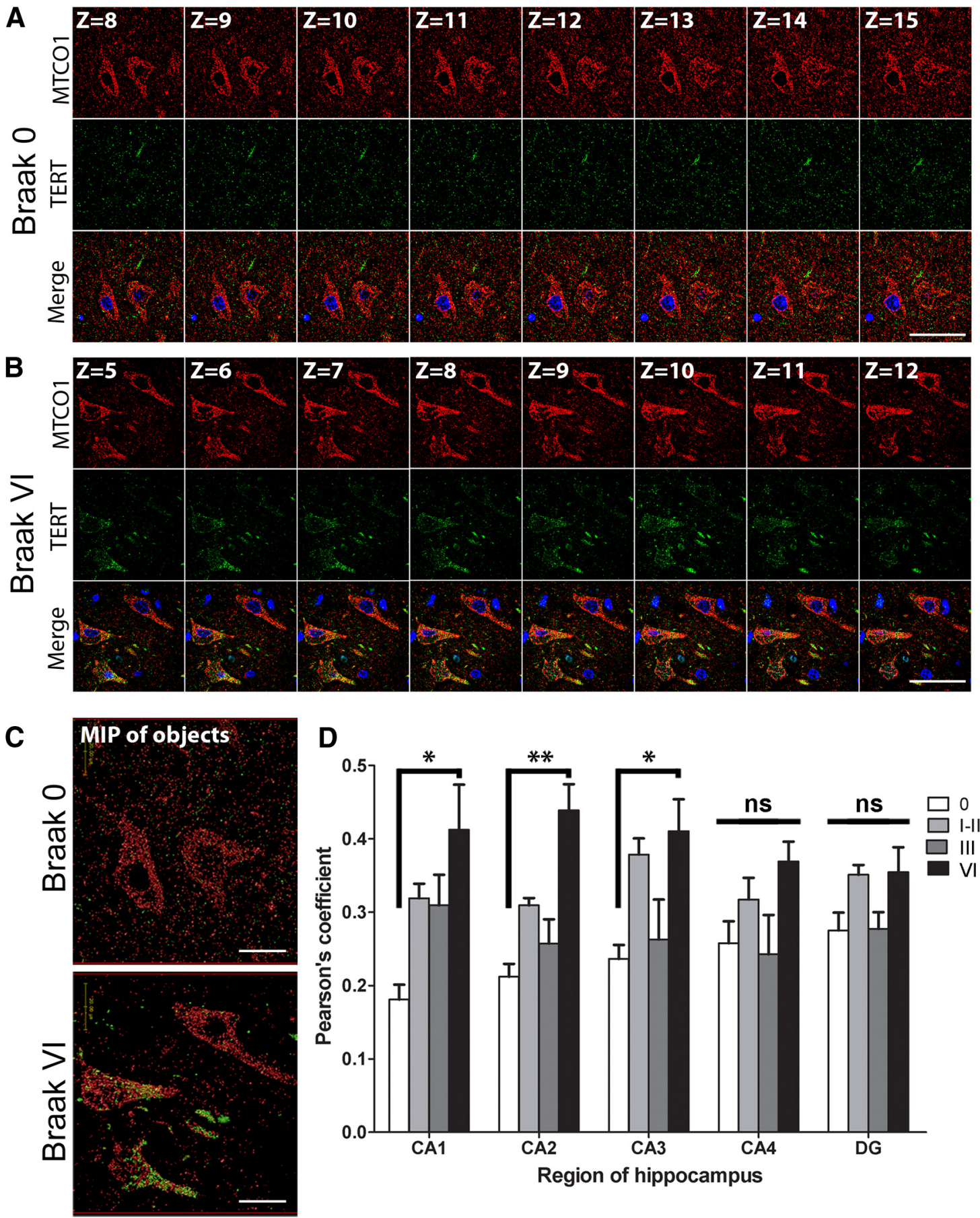

Figure 3. TERT protein colocalizes with mitochondria under AD pathology. Representative series of sequential confocal images showing immunofluorescent labeling of TERT (green) and mitochondria (MTC01, red) in CA2 hippocampal neurons from $(\boldsymbol{A})$ a control and (B) a Braak Stage VI case (DAPI, blue). Images shown are from the middle section of Z-stacks containing a total of $20-24$ planes. C, Maximum intensity projection images of TERT and mitochondria derived from Z-stack series covering the total section depth. D, Bar graphs represent Pearson's coefficients indicating the degree of colocalization between TERT and mitochondria in CA1, CA2, CA3, CA4, and DG regions of the hippocampus. Colocalization was increased in the CA1, CA2, and CA3 regions of $\mathrm{AD}$ (Braak VI) cases compared with the control group. Data are mean \pm SEM from 3 cases per group. ${ }^{*} p<0.05$ (one-way ANOVA with Tukey's post hoc test). ${ }^{* *} p<0.01$ (one-way ANOVA with Tukey's post hoc test). ns, Not significant. Scale bars, $50 \mu \mathrm{m}$; maximum intensity projection image, $20 \mu \mathrm{m}$.

apoptosis (Fu et al., 2000; Zhu et al., 2000; Lu et al., 2001). These findings suggest that TERT protein has protective functions in neurons. Thus, we hypothesized that neurons cultured from TERT ${ }^{-/-}$ mice would be less resistant to oxidative stress than wild-type neurons. Neurons from both genotypes were exposed to hydrogen peroxide, and mitochondrial superoxide production was measured using DHE. As expected, $\mathrm{H}_{2} \mathrm{O}_{2}$ treatment led to a small but signifi- cant increase in DHE fluorescence of $66 \pm 3.7 \%$ in $T_{E R T}{ }^{-/-}$neurons compared with untreated controls (Fig. $6 A ; p=0.035$ ). There was no difference in the levels of superoxide in wild-type neurons exposed to $\mathrm{H}_{2} \mathrm{O}_{2}$ compared with the untreated controls. In addition, we did not find any difference in the DHE levels between the two genotypes without oxidative stress. These data support previous findings that TERT protects cells (Ahmed et al., 2008; Haendeler et 
A
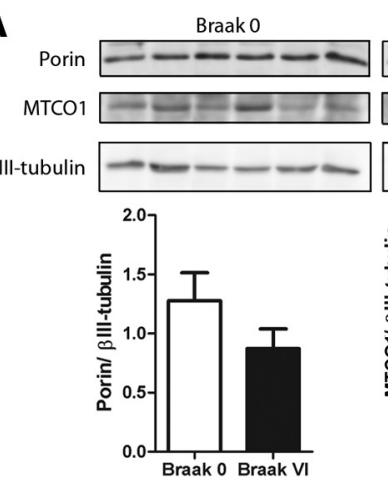

Braak VI
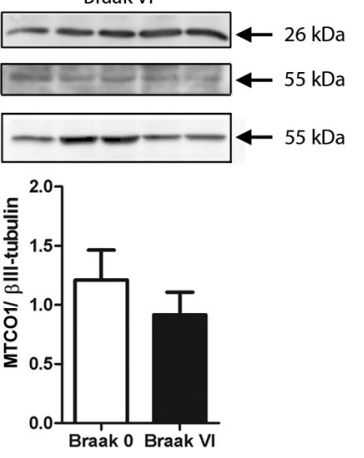

C

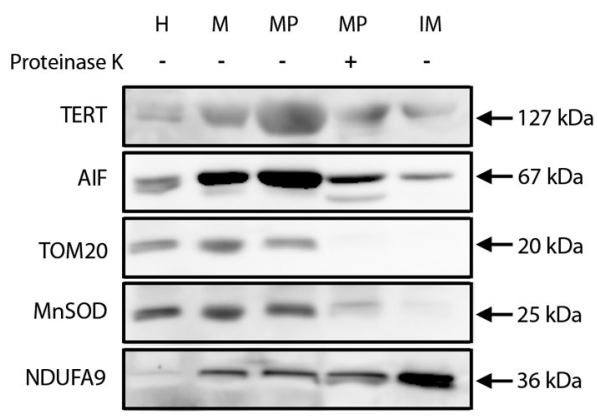

B

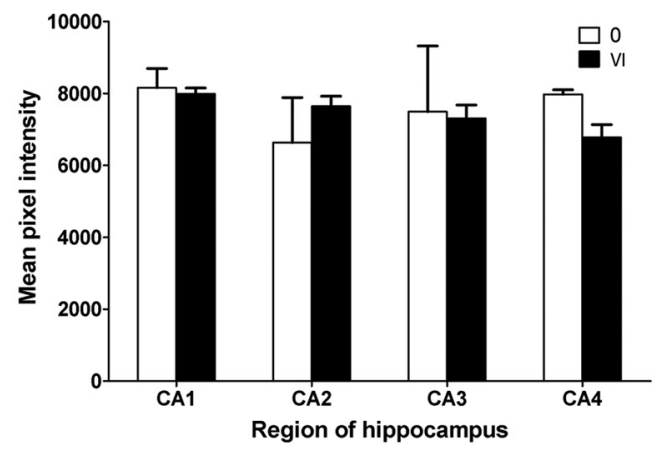

Figure 4. Levels of mitochondrial proteins are unchanged in AD. $A$, Western blots for mitochondrial proteins were performed with lysates from controls and from AD cases (Braak Stage VI). There were no significant differences in levels of VDAC/porin or MTC01 protein $(n=5$ or $6, p>0.05)$. Data are mean \pm SEM and were analyzed using a two-sample $t$ test. $\boldsymbol{B}$, Histogram showing quantification of MTC01-immunolabeled hippocampal sections. There are no significant differences in fluorescence intensity between control and AD cases $(n=3, p>0.05)$. Scale bars, $50 \mu$ m. $C$, Mouse liver mitochondria were isolated, then subfractionated into mitoplast, proteinase K-shaved mitoplast, and inner membrane fractions. Western blots show appropriately sized bands representing mTERT (127 kDa) and the mitochondrial marker proteins: AlF ( $67 \mathrm{kDa}$; matrix/inner mitochondrial membrane), TOM20 (20 kDa; outer mitochondrial membrane/intermembrane space), MnSOD (25 kDa; matrix), and NDUFA9 (36 kDa; inner mitochondrial membrane). TERT protein expression is found in all fractions. H, Liver homogenate; $M$, pure mitochondria; MP, mitoplast; IM, inner mitochondrial membrane.

al., 2009), and suggest that a loss of TERT may result in an increased susceptibility to oxidative damage.

Oxidative stress induces mitochondrial localization of TERT in cultured neurons

Under conditions of oxidative stress, TERT has previously been shown to shuttle to mitochondria (Santos et al., 2004; Ahmed et al., 2008; Haendeler et al., 2009; Singhapol et al., 2013) and decrease ROS production and mitochondrial DNA damage, increase mitochondrial membrane potential (Ahmed et al., 2008), and improve $\mathrm{Ca}^{2+}$ uptake in different cell types, including neurons (Kang et al., 2004). To investigate whether TERT shuttles to mitochondria in our cultured neurons following oxidative stress, wild-type neurons were exposed to hydrogen peroxide and colocalization analysis was performed using anti-TERT and antiMTCO1 antibodies (Fig. 6C). In neurons exposed to hydrogen peroxide, TERT colocalization with mitochondria was increased compared with untreated control $(64 \pm 4.8 \%, p=0.017)$ (Fig. $6 B)$. A smaller amount of TERT protein was found to be localized at the nucleus, and this was unchanged following exposure to hydrogen peroxide (Fig. 5B). To check whether TERT is localized at other major cellular compartments, immunofluorescent staining of endoplasmic reticulum (ER) was performed using an anticalnexin antibody. There was no substantial colocalization between TERT and the ER (Fig. 6D).

We observed a mutual exclusion of pathological tau and TERT in human hippocampal neurons and hypothesized that this might be due to a downregulation of TERT expression following tau pathology. However, in cultured neurons transduced with empty vector, truncated tau, or mutated tau, we did not observe differences in levels of TERT protein (Fig. 6E, G). In addition, mitochondrial content was unchanged in tau transduced neurons (Fig. 6F).

\section{TERT protects against tau pathology in vitro}

Pathological tau increases mitochondrial superoxide in TERT ${ }^{-1-}$ neurons

To investigate whether TERT protein reduces oxidative damage induced by pathological tau, neurons from wild-type and TERT $T^{-/-}$mice were cultured and transduced with lentiviral vectors containing two pathological tau variants: truncated tau (151-391aa) and mutated (P301L) tau. Following transduction with either truncated tau or P310L tau, the AT8 antibody specifically labeled the dendrites of neurons, with less intense staining of the somata (Fig. 7A, left image). Neuronal transduction was optimized, achieving high efficiency as shown by the mCherry reporter plasmid (Fig. 6A, second image). In transduced neurons from wild-type and TERT $T^{-/-}$mice, $\mathrm{Mi}$ toSOX staining was measured in the soma, apical, and basal dendrites (Fig. 6B, C). The MitoSOX signal was increased by $63 \pm 9.6 \%$ in the basal dendrites of TERT ${ }^{-/-}$neurons transduced with mutated tau compared with wild-type (Fig. $7 E ; p=$ 0.013 ), although no significant differences were seen in other cell areas or in neurons transduced with truncated tau (Fig. 6D). There were no significant differences in MitoSOX intensity between neurons from the two genotypes when transduced with truncated tau. 

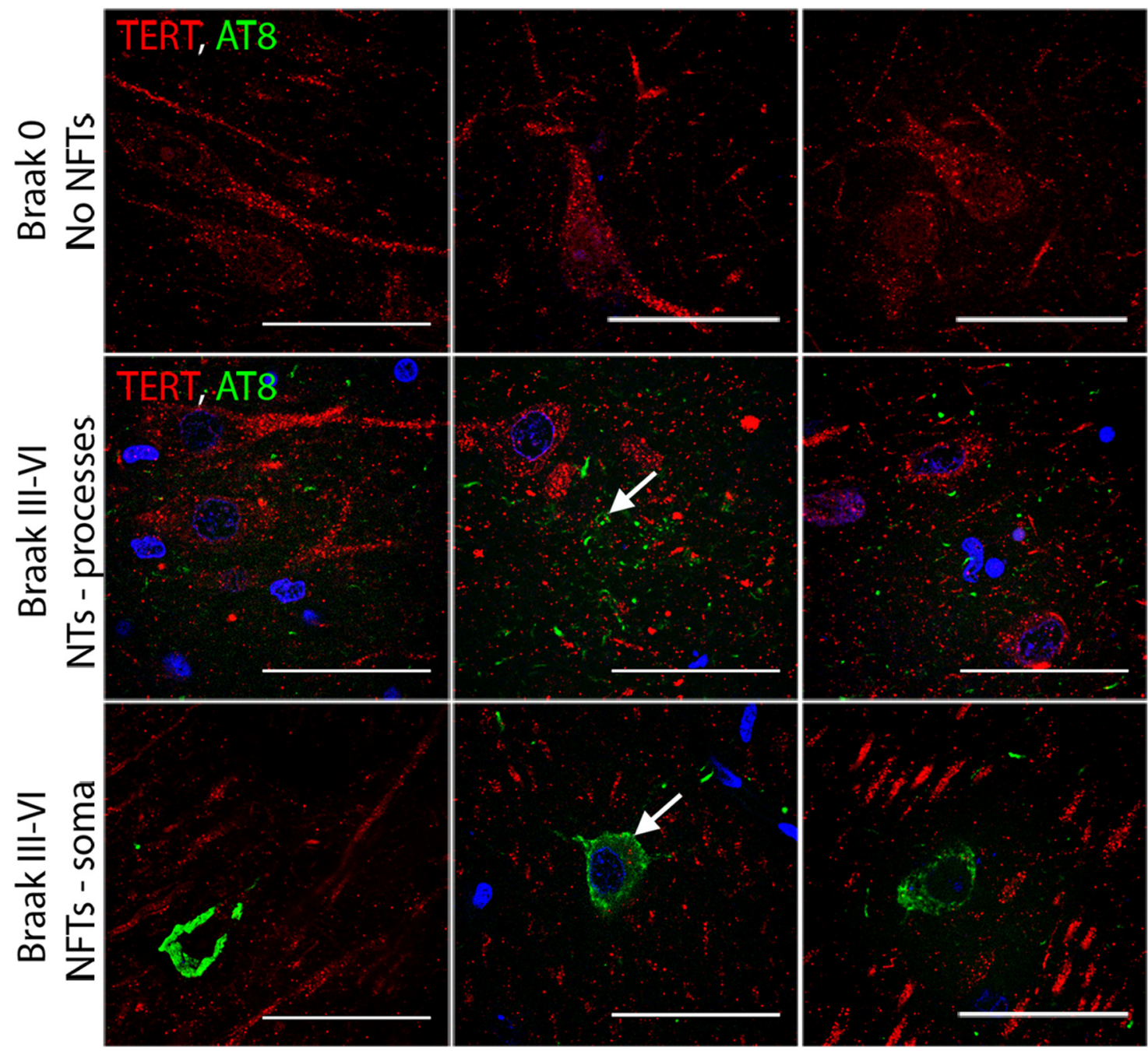

Figure 5. TERT and pathological tau mutually exclude each other. Sections from Braak Stage 0 and Braak Stages III-VI were labeled for TERT (red) and pathological tau (AT8; green). In the control cases, TERT immunoreactivity is present; however, AT8 staining is absent. In cases with higher Braak stages, AT8 staining is seen as NTs in dendrites and NFTs in the soma. Tangle-bearing neurons are not immunoreactive for TERT, and TERT-expressing neurons do not contain AT8. Scale bars, $50 \mu \mathrm{m}$.

Pathological tau increases lipid peroxidation in TERT ${ }^{-1-}$ neurons Increased production of mitochondrial superoxide causes oxidation of cellular structures, including lipid membranes (Sayre et al., 1997), proteins (Perluigi et al., 2009), and mitochondrial and nuclear DNA (Lovell and Markesbery, 2007). Hence, we expected that TERT ${ }^{-1-}$ neurons would display higher levels of lipid peroxidation in response to pathological tau than wild-type. 4-HNE staining was increased by $76 \pm 17.7 \%$ in the soma of TERT ${ }^{-/-}$ neurons transduced with mutated tau compared with wild-type (Fig. $8 D ; p=0.029$ ), although no changes were found in the dendrites. There were no significant differences between genotypes when transduced with truncated tau (Fig. 8C). This result is in accordance with the increased oxidative stress seen in TERT ${ }^{-/-}$neurons after transduction with mutated, but not with truncated tau.

\section{Discussion}

\section{TERT expression in the human brain}

In rodent brain, telomerase activity is high during embryonic development but quickly downregulated postnatally (Klapper et al., 2001). However, expression of TERT has been described to persist into adulthood in mouse and rat (Klapper et al., 2001; Lee et al., 2010; Eitan et al., 2012b), and in neurons specifically (Eitan et al., 2012a). However, little is known about TERT expression in adult human brain. We demonstrated that TERT protein is expressed in the cytoplasm of neurons of the CA1, CA2, CA3, CA4, and DG regions of the adult hippocampus. We found that activated microglial cells express TERT protein, corresponding to previous findings in mice (Fu et al., 2002b; Flanary and Streit, 2005). Astrocytes did not express TERT, which is also in accordance with previous findings in developing mouse cortex and hippocampus (Fu et al., 2000).

In primary neurons, we found that telomerase activity was lost $\sim 11 \mathrm{~d}$ in culture (Fig. 1E), whereas TERT protein expression persisted (Fig. 1B) corresponding to previous observations (Fu et al., 2002a). We expected a reduction in neuronal TERT expression with progression through increasing Braak stages to clinical $\mathrm{AD}$, leading to susceptibility to pathology, similar to findings in a mouse model of ALS (Eitan et al., 2012b). However, we found no changes in TERT protein expression in hippocampus of early Braak stage cases (I-III) or in AD cases compared with healthy age-matched controls using three independent methods.

\section{TERT and mitochondria in AD brain}

In dividing cells, TERT is known to be exported from the nucleus and to enter mitochondria upon cellular stress (Santos et al., 
A

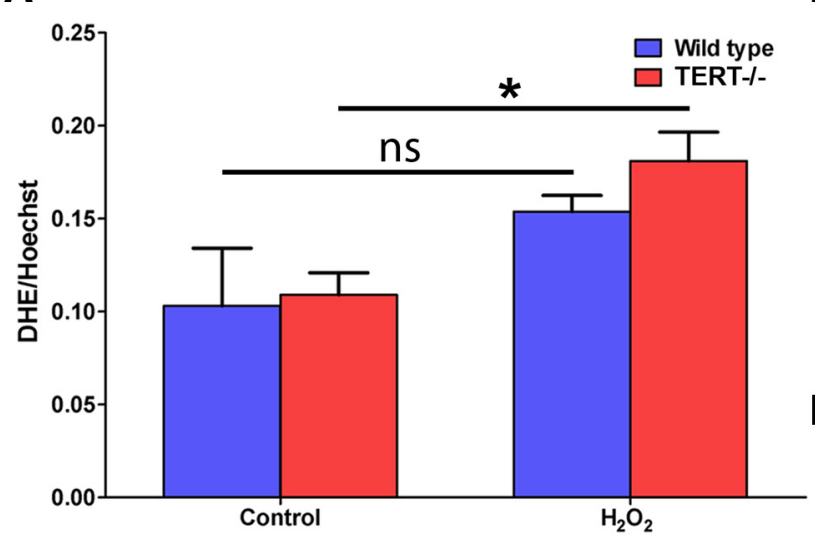

B

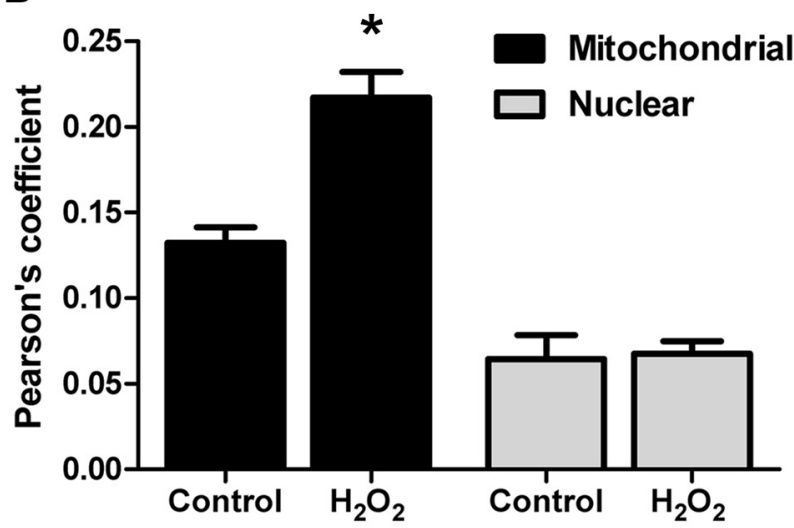

E

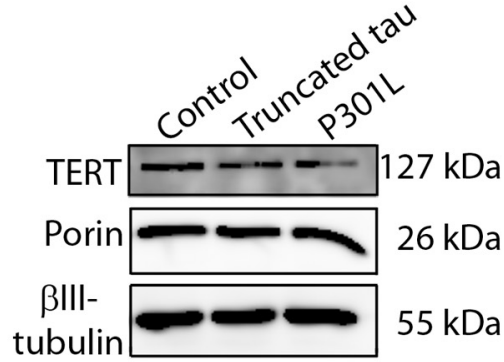

$\mathbf{F}$

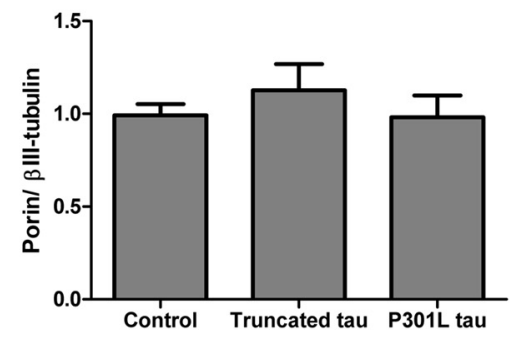

G

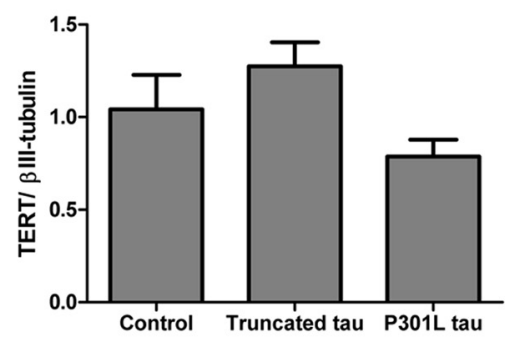

C
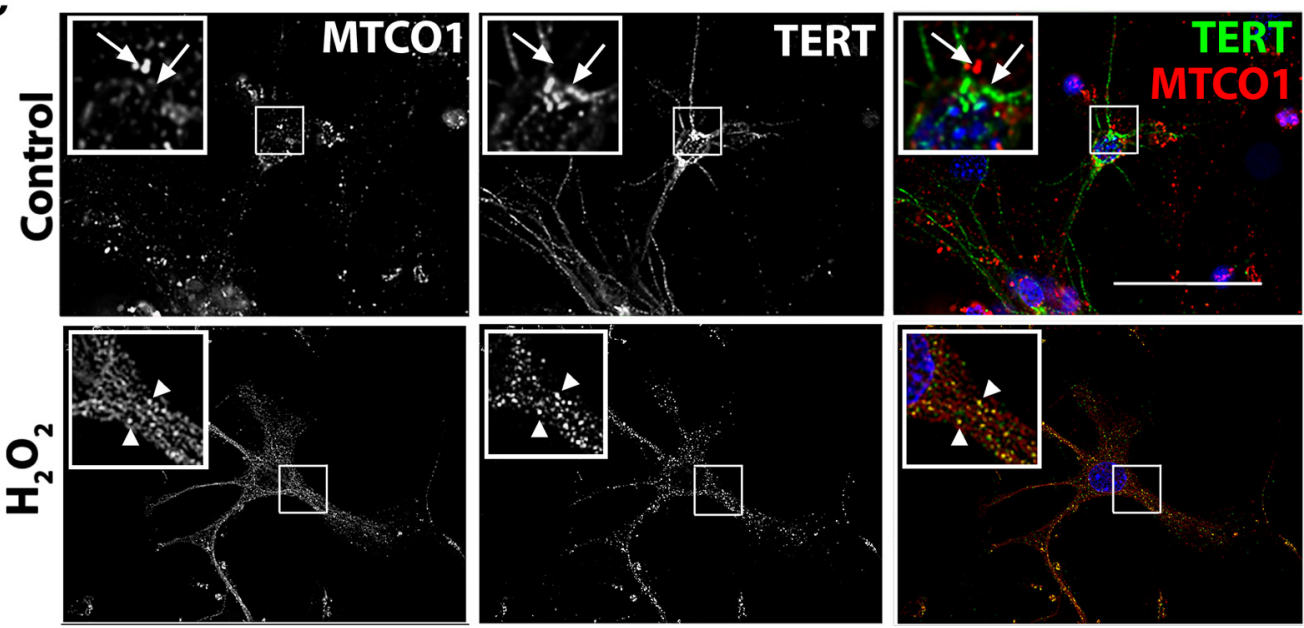

D
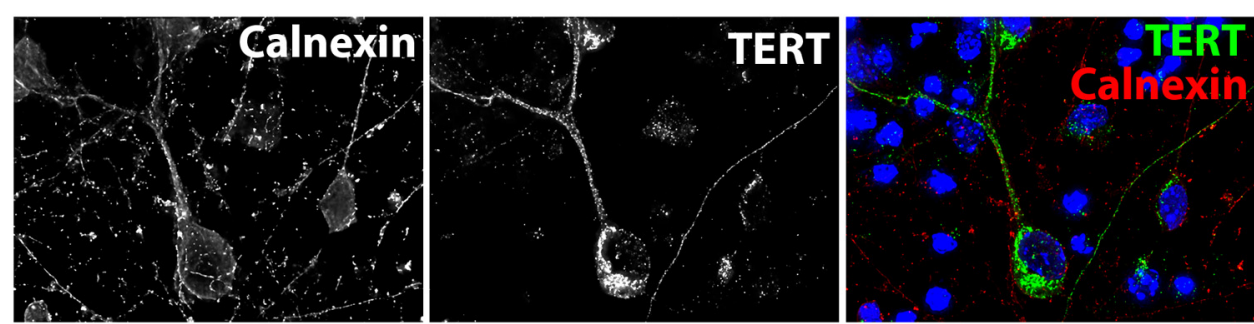

Figure 6. Neurons lacking TERT have an increased susceptibility to oxidative stress. $A$, Cultured neurons were exposed to hydrogen peroxide, and the production of superoxide was measured using DHE. DHE levels were increased in TERT ${ }^{-/}$neurons exposed to hydrogen peroxide compared with control. ${ }^{*} p<0.05$ (two-sample $t$ test). Data are mean \pm SEM from three independent experiments. ns, Not significant. $\boldsymbol{B}$, Oxidative stress increases mitochondrial localization of TERT in cultured neurons. ${ }^{*} p<0.05$ (two-sample $t$ test). Wild-type (Figure legend continues.) 
2004; Ahmed et al., 2008; Haendeler et al., 2009). In neurons of the human hippocampus, we detected the majority of TERT outside the nucleus, which could be due to them being postmitotic and without need for telomere maintenance. Iannilli et al. (2013) showed that TERT levels increased in the cytoplasm and decreased in the nucleus in cultured hippocampal rat neurons with time in vitro. The same authors demonstrated that TERT forms a complex with p15 mRNA preventing its translation in the cytoplasm of neurons. Upon oxidative stress, this complex is resolved, p15 translated, and TERT is free move to the mitochondria (Iannilli et al., 2013). Thus, we suggest that neuronal TERT might be localized preferentially in the cytoplasm and move to mitochondria under conditions of increased oxidative stress.

We found a greater proportion of TERT protein colocalized with mitochondria in hippocampal neurons of the CA1, CA2 and CA3 at Braak Stage VI, compared with the same region in controls. Mammalian TERT protein contains a mitochondrial leader sequence, which allows interaction with the translocase complexes and entry into the mitochondrial matrix (Santos et al., 2004; Haendeler et al., 2009; Sharma et al., 2012). Within the mitochondria, TERT has been shown to reduce cellular ROS production and improve mitochondrial function as well as to reduce apoptosis after cellular stress (Ahmed et al., 2008; Haendeler et al., 2009; Singhapol et al., 2013). Our results suggest that, under the cellular stress resulting from AD pathology, TERT moves to mitochondria where it may improve respiratory chain function and to decrease ROS levels. In a transgenic mouse model of $\mathrm{AD}$, amyloid $\beta(\mathrm{A} \beta)$ was shown to cause complex IV deficits, whereas tau pathology specifically affected complex I (Rhein et al., 2009). Because TERT has been shown to improve complex I activity (Haendeler et al., 2009), one could speculate that there might be a direct functional interaction of both proteins at this mitochondrial site. When we investigated TERT protein expression in different mitochondrial fractions from mouse liver, we found enrichment of TERT in the mitochondria. In addition, TERT was found in mitochondrial subfractions up to and including at the inner membrane. These data correspond to previous findings by others that TERT is imported into the organelles (Haendeler et al., 2009; Sharma et al., 2012).

\section{TERT and tau in AD brain}

Two of the features commonly observed in the $\mathrm{AD}$ brain are compromised energy production (Atamna and Frey, 2007) and formation of neurofibrillary tangles, as a result of hyperphosphorylation of tau (Grundke-Iqbal et al., 1986). The two could be causally linked because an impairment of mitochondrial function leads to increased ROS production, which may promote hyperphosphorylation of tau (Melov et al., 2007). In turn, forma-

\section{$\leftarrow$}

(Figure legend continued.) neurons were exposed to hydrogen peroxide and analyzed for colocalization between TERT and MTC01 or TERT and the nuclear stain, DAPI. Data are mean \pm SEM from three independent experiments. $C$, Representative images showing TERT and MTCO1 immunofluorescent labeling of neurons in culture. White arrowheads indicate regions of colocalization. White arrows indicate absence of colocalization. Inset, $2 \times$ magnification. $\boldsymbol{D}$, Immunofluorescent labeling of cultured neurons with calnexin (red) and TERT (green) shows that the majority of TERT does not colocalize with endoplasmic reticulum. Scale bars, $50 \mu \mathrm{m}$. $\boldsymbol{E}$, Representative Western blot showing specific bands for TERT and the mitochondrial protein porin in cultured neurons, transduced with vector control, truncated tau, or mutated tau. F, Quantification of Western blot shows no differences in level of TERT protein between groups $(n=4)$. $\mathbf{G}$, Quantification of Western blot shows no differences in the level of porin protein expression between groups. Data are mean \pm SEM from four independent experiments, analyzed using one-way ANOVA. tion of hyperphosphorylated tau could also impair retrograde mitochondrial movement along microtubules (Ebneth et al., 1998) and so lead to ATP depletion in the axons and dendrites, resulting in synaptic dysfunction (Mattson and Liu, 2002). At present, it remains unclear which of these two processes, oxidative stress or hyperphosphorylation of tau, occurs first.

In the hippocampus of patients with Braak Stage III and VI pathology, we observed a mutual exclusion of TERT and both neuropil threads and neurofibrillary tangles. In contrast, control brains (Braak Stage 0) displayed only TERT-positive neurons. This suggests that either TERT expressing neurons are prevented from developing tau pathology or that TERT protein is lost following formation of NTs and NFTs. In cultured mouse neurons, we found that TERT expression was unaffected by transduction with truncated and mutated tau. However, it cannot be excluded that pathological tau causes a downregulation of TERT protein when expressed over a longer time period. Although we did not find obvious changes in TERT protein levels in AD brains, there was a subcellular redistribution of TERT to more mitochondrial localization in Braak Stage VI cases.

\section{TERT in an in vitro model of tau pathology}

Comparing neurons from wild-type and TERT ${ }^{-1-}$ mice, we found that the absence of TERT protein resulted in increased mitochondrial superoxide production following exposure to hydrogen peroxide. We sought to analyze whether TERT protein also protected against pathological tau in cultured neurons. $\mathrm{Mu}-$ tations in the tau gene, such as P301L in frontotemporal dementia, cause neurodegeneration through hyperphosphorylation of tau, which translocates to somatodendritic areas and forms aggregates as NFT (Hutton et al., 1998; Varani et al., 1999; David et al., 2005; Götz and Ittner, 2008). Truncated tau species have also been shown to associate with NFTs in AD and contribute to neuronal dysfunction (Mena et al., 1996; Cente et al., 2006; Zilkova et al., 2011). Both forms can be hyperphosphorylated and form aggregates in vitro and in animal models of AD (Götz et al., 2001; Cente et al., 2006; Zilka et al., 2006; Bi et al., 2011; Zilkova et al., 2011; Giustiniani et al., 2014). In one recent study, injection of a lentivirus containing P301L tau into the brains of mice resulted in tau phosphorylation at sites important for paired helical filament formation, including Thr 181 (AT270) and Ser 262, whereas wild-type tau had no such effect (Biernat et al., 1993; Khandelwal et al., 2012). In sporadic AD, it is wild-type tau that is associated with development of pathology. There are a number of mouse models available which use wild-type tau to mimic sporadic AD (Götz et al., 1995; Brion et al., 1999; Probst et al., 2000; Andorfer et al., 2005; Jaworski et al., 2009; Caillierez et al., 2013; Dujardin et al., 2014). However, we chose not to use the fulllength tau because generally its cytotoxic effects in vitro are less pronounced than the mutated or truncated tau forms (Abraha et al., 2000; Fath et al., 2002; Khlistunova et al., 2006).

Therefore, we tested the protective effects of TERT against truncated tau and P301L mutant tau. Importantly, we found increased mitochondrial superoxide generation and lipid peroxidation in TERT ${ }^{-1-}$ neurons transduced with mutated P301L tau. Increased mitochondrial superoxide was detected in the dendrites of TERT ${ }^{-1-}$ neurons. Normally, dendrites of cultured neurons are devoid of tau. We suggest that tau hyperphosphorylation in the dendrites results in increased MitoSOX due to dysfunctional trafficking of mitochondria along these processes. Lipid peroxidation was increased in the neuronal somata of TERT $^{-/-}$neurons transduced with mutated P301L tau, compared with wild-type. This is likely due to the cell body containing 
A
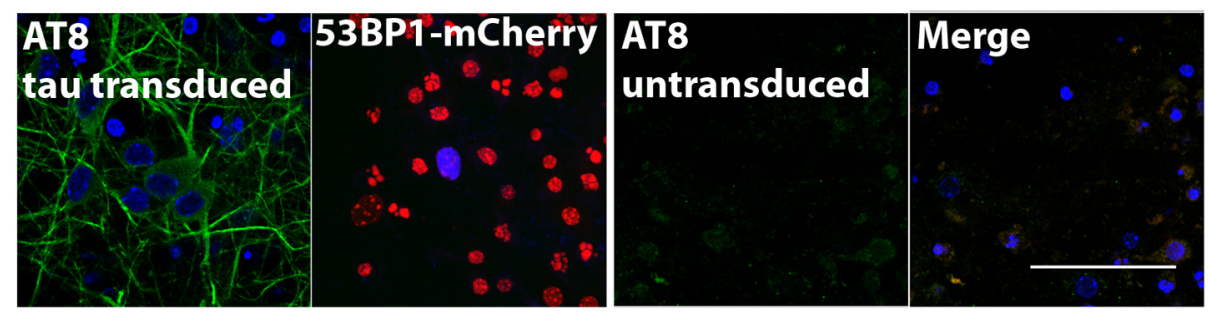

B

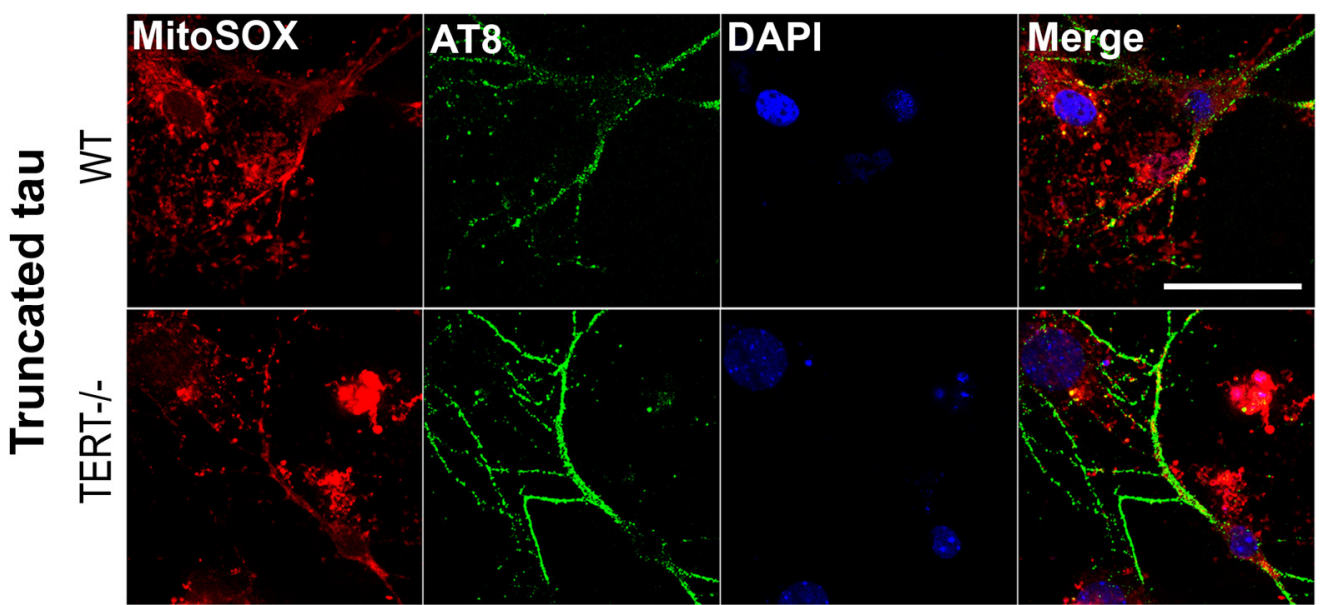

C

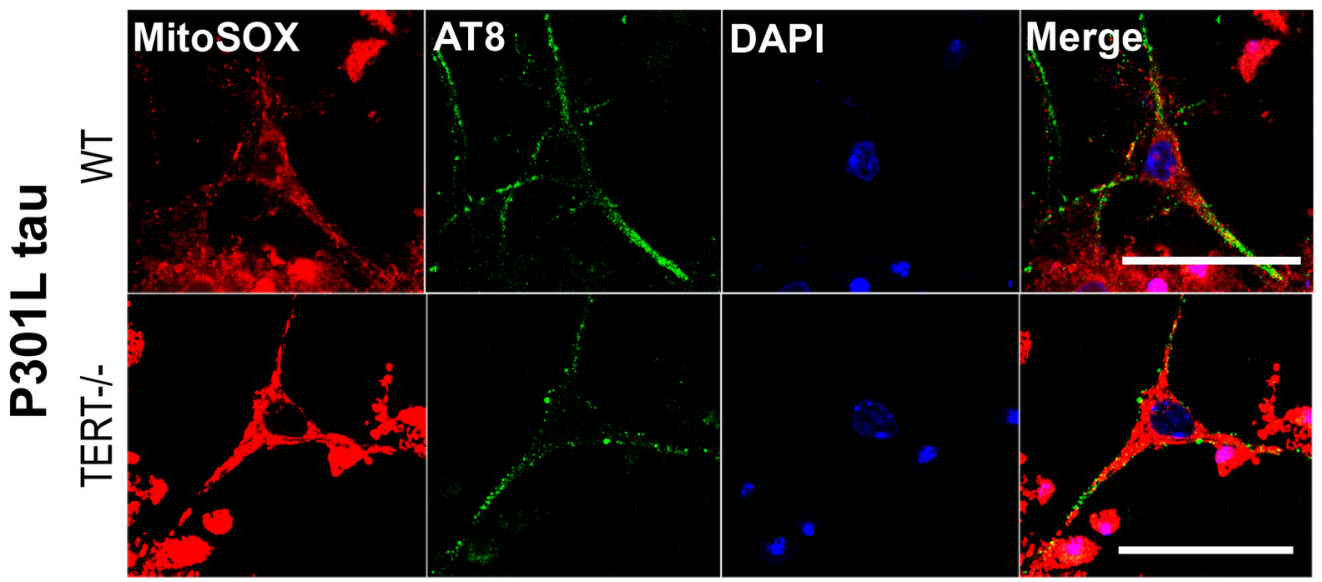

D

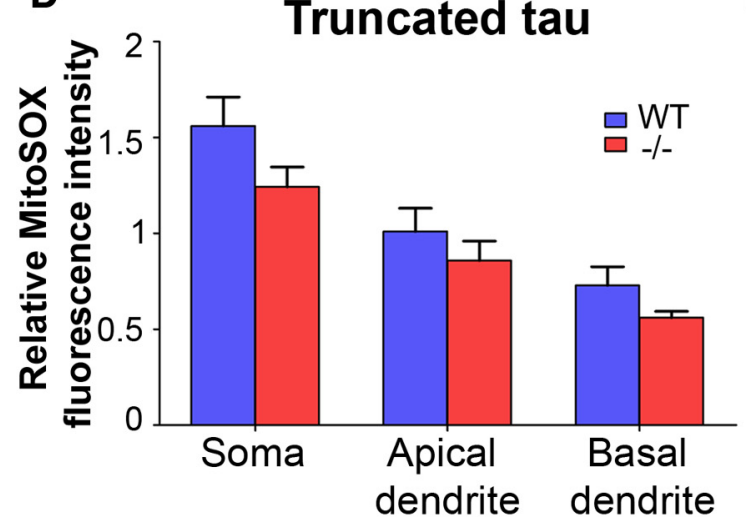

E

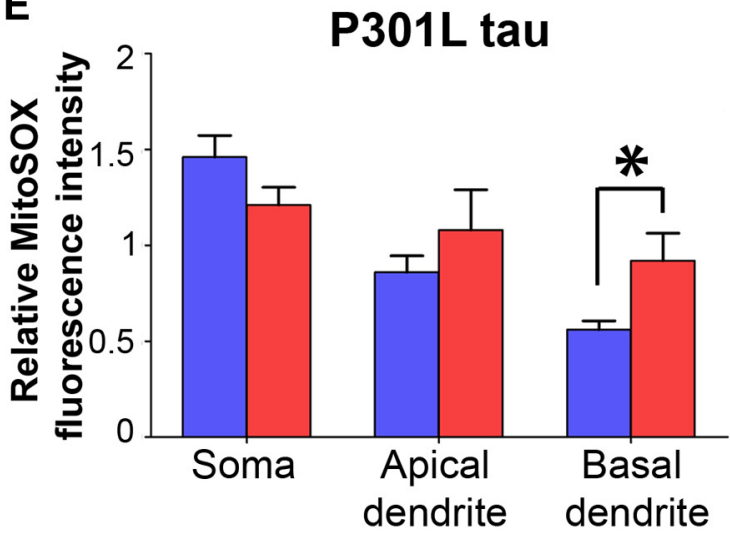

Figure 7. Pathological tau increases mitochondrial superoxide in TERT ${ }^{-/-}$neurons. A, A high proportion of P301L-transduced neurons are labeled with AT8 (green; left). The optimal transduction efficiency was determined using a fluorescent reporter lentivirus. Neurons transduced with lentivirus-containing 53BP1-mCherry were $\gamma$-irradiated to induce DNA damage. The majority of cells were transduced, as indicated by the nuclei containing 53BP1 foci (red; second panel). Untransduced neurons do not label with anti-AT8 antibody. B, C, Neurons from wild-type and TERT ${ }^{-1-}$ mice were transduced with either truncated tau (B) or mutated tau (C). Double-labeling with MitoSOX (red) and anti-AT8 (green) was conducted, and levels of superoxide were measured in three cell areas: the soma, apical dendrites, and basal dendrites. $\boldsymbol{D}$, There were no differences in MitoSOX fluorescence between wild-type and TERT ${ }^{-1-}$ neurons transduced with truncated tau. $E$, MitoSOX fluorescence was increased in the dendrites of TERT ${ }^{-1-}$ neurons transduced with mutated tau. ${ }^{*} p<0.05$ (one-way ANOVA with Tukey's posthoctest). Data are mean \pm SEM from three independent experiments. 
A

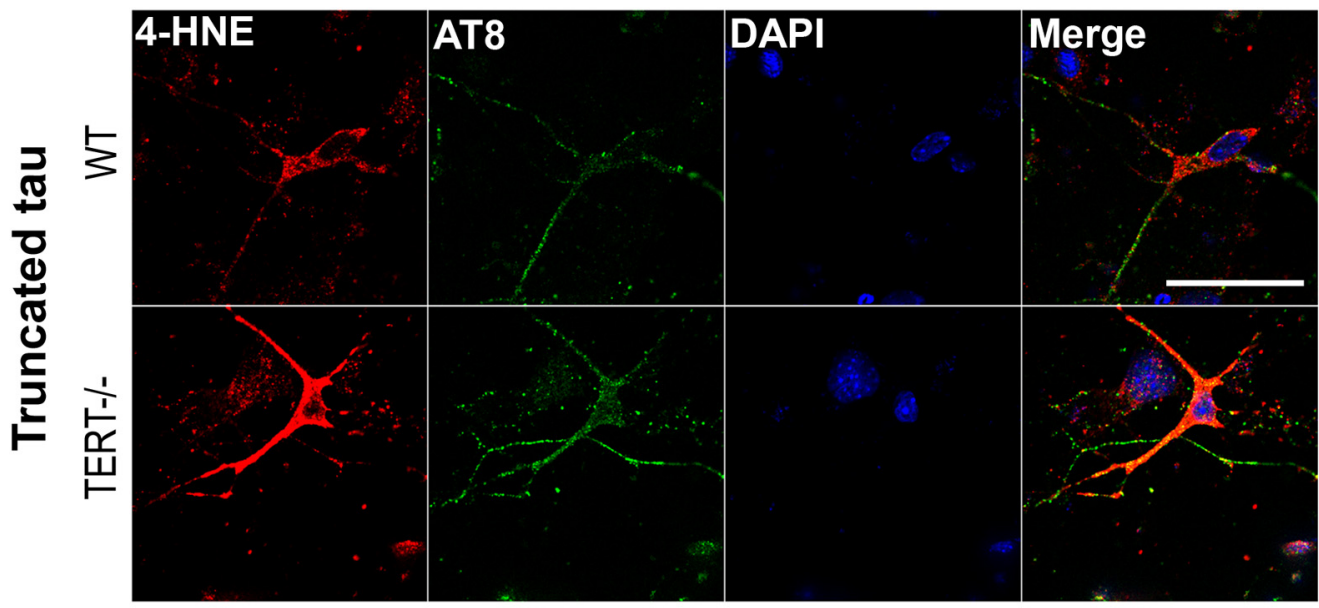

B

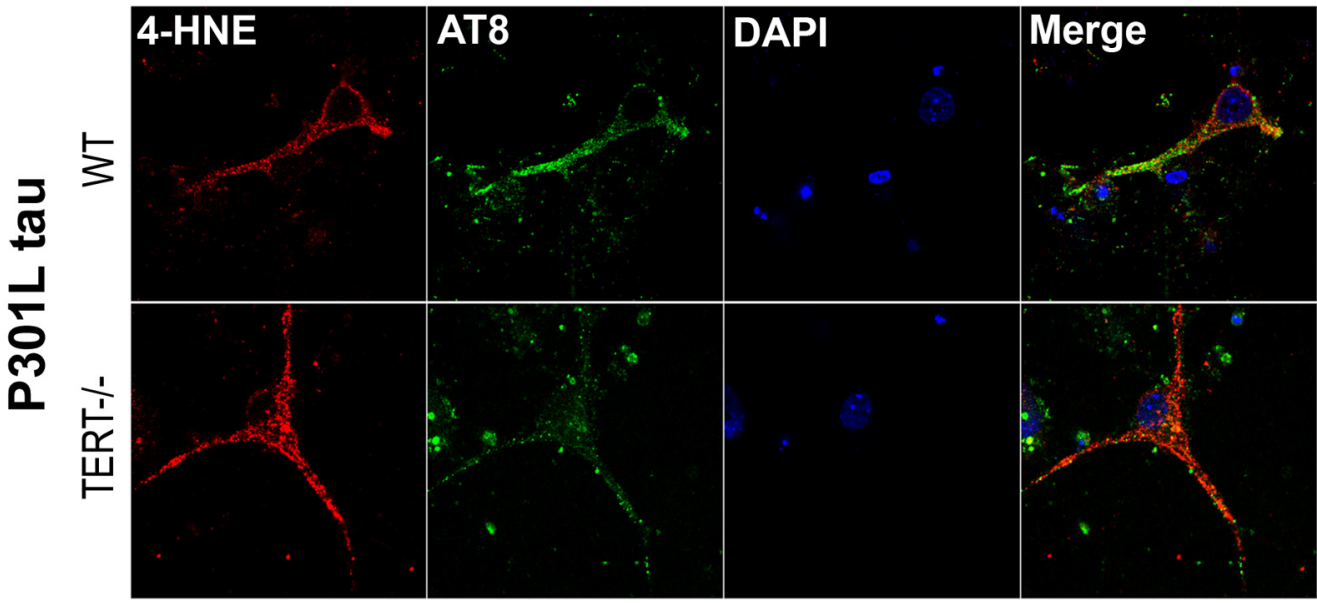

C

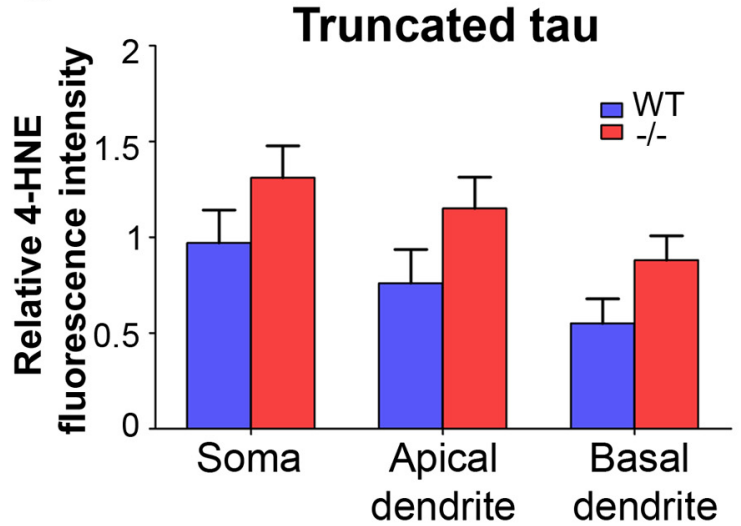

D

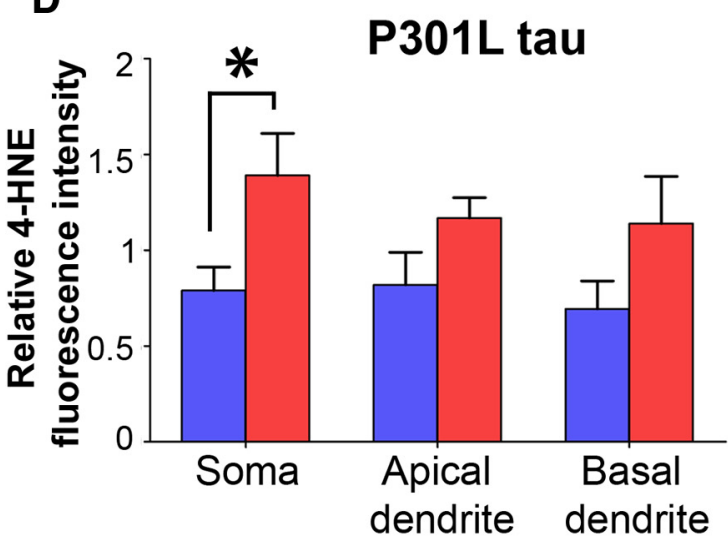

Figure 8. Pathological tau increases lipid peroxidation in TERT ${ }^{-/-}$neurons. Neurons from wild-type and TERT ${ }^{-/-}$mice were transduced with either truncated $(\boldsymbol{A})$ or mutated $(\boldsymbol{B})$ tau. Double-labeling with 4-HNE (red) and AT8 (green) was performed, and levels of lipid peroxidation were measured in the soma, apical dendrites, and basal dendrites. $C$, There were no differences in 4-HNE levels between wild-type and TERT ${ }^{-1-}$ neurons transduced with truncated tau. D, 4-HNE was increased in the soma of $T E R T^{-1-}$ neurons transduced with mutated tau. ${ }^{*} p<0.05$ (one-way ANOVA with Tukey's post hoc test). Data are mean \pm SEM from three independent experiments. Scale bars, $50 \mu \mathrm{m}$.

the highest concentration of lipid membranes. Interestingly, levels of superoxide and lipid peroxidation were not significantly different between wild-type and TERT $T^{-/-}$neurons transduced with truncated tau. Expression of truncated tau has been described to generate increased oxidative stress previously over a longer time course (Cente et al., 2006). Although we found tau hyperphosphorylation, the truncated tau protein, might need more time to affect ROS generation. These data demonstrate that there might be differences in the kinetics or mechanism of ROS induction between the two tau forms.
Together, our results suggest that the telomerase protein TERT seems to be a protective factor in the brain and may offer neuronal resistance against pathological tau by reducing production of oxidative species and improving mitochondrial function. New telomerase activating compounds have been described, one of which was shown to be effective in reducing disease symptoms and extending lifespan in a mouse model of ALS (Eitan et al., 2012b). These telomerase activators could form a basis for novel preventative treatments for neurodegenerative diseases. 


\section{Notes}

Supplemental material for this article is available at http://dev-research. ncl.ac.uk/saretzki/. This material has not been peer reviewed.

\section{References}

Abraha A, Ghoshal N, Gamblin TC, Cryns V, Berry RW, Kuret J, Binder LI (2000) C-terminal inhibition of tau assembly in vitro and in Alzheimer's disease. J Cell Sci 113:3737-3745. Medline

Ahmed S, Passos JF, Birket MJ, Beckmann T, Brings S, Peters H, BirchMachin MA, von Zglinicki T, Saretzki G (2008) Telomerase does not counteract telomere shortening but protects mitochondrial function under oxidative stress. J Cell Sci 121:1046-1053. CrossRef Medline

Alonso AC, Grundke-Iqbal I, Iqbal K (1996) Alzheimer's disease hyperphosphorylated tau sequesters normal tau into tangles of filaments and disassembles microtubules. Nat Med 2:783-787. CrossRef Medline

Andorfer C, Acker CM, Kress Y, Hof PR, Duff K, Davies P (2005) Cell-cycle reentry and cell death in transgenic mice expressing nonmutant human tau isoforms. J Neurosci 25:5446-5454. CrossRef Medline

Atamna H, Frey WH 2nd (2007) Mechanisms of mitochondrial dysfunction and energy deficiency in Alzheimer's disease. Mitochondrion 7:297-310. CrossRef Medline

Attwell D, Laughlin SB (2001) An energy budget for signaling in the grey matter of the brain. J Cereb Blood Flow Metab 21:1133-1145. CrossRef Medline

Barnham KJ, Masters CL, Bush AI (2004) Neurodegenerative diseases and oxidative stress. Nat Rev Drug Discov 3:205-214. CrossRef Medline

Basurto-Islas G, Luna-Muñoz J, Guillozet-Bongaarts AL, Binder LI, Mena R, García-Sierra F (2008) Accumulation of aspartic acid421-and glutamic acid391-cleaved tau in neurofibrillary tangles correlates with progression in Alzheimer disease. J Neuropathol Exp Neurol 67:470-483. CrossRef Medline

Beal MF (2005) Mitochondria take center stage in aging and neurodegeneration. Ann Neurol 58:495-505. CrossRef Medline

Bi M, Ittner A, Ke YD, Götz J, Ittner LM (2011) Tau-targeted immunization impedes progression of neurofibrillary histopathology in aged P301L tau transgenic mice. PLoS One 6:e26860. CrossRef Medline

Biernat J, Gustke N, Drewes G, Mandelkow EM, Mandelkow E (1993) Phosphorylation of Ser262 strongly reduces binding of tau to microtubules: distinction between PHF-like immunoreactivity and microtubule binding. Neuron 11:153-163. CrossRef Medline

Braak H, Braak E (1991) Neuropathological staging of Alzheimer-related changes. Acta Neuropathol 82:239-259. CrossRef Medline

Braak H, Alafuzoff I, Arzberger T, Kretzschmar H, Del Tredici K (2006) Staging of Alzheimer disease-associated neurofibrillary pathology using paraffin sections and immunocytochemistry. Acta Neuropathol 112:389404. CrossRef Medline

Brion JP, Tremp G, Octave JN (1999) Transgenic expression of the shortest human tau affects its compartmentalization and its phosphorylation as in the pretangle stage of Alzheimer's disease. J Pathol 154:255-270. CrossRef Medline

Caillierez R, Bégard S, Lécolle K, Deramecourt V, Zommer N, Dujardin S, Loyens A, Dufour N, Aurégan G, Winderickx J, Hantraye P, Déglon N, Buée L, Colin M (2013) Lentiviral delivery of the human wild-type tau protein mediates a slow and progressive neurodegenerative tau pathology in the rat brain. Mol Ther 21:1358-1368. CrossRef Medline

Caporaso GL, Lim DA, Alvarez-Buylla A, Chao MV (2003) Telomerase activity in the subventricular zone of adult mice. Mol Cell Neurosci 23:693702. CrossRef Medline

Cente M, Filipcik P, Pevalova M, Novak M (2006) Expression of a truncated tau protein induces oxidative stress in a rodent model of tauopathy. Eur J Neurosci 24:1085-1090. CrossRef Medline

Chiang YJ, Hemann MT, Hathcock KS, Tessarollo L, Feigenbaum L, Hahn WC, Hodes RJ (2004) Expression of telomerase RNA template, but not telomerase reverse transcriptase, is limiting for telomere length maintenance in vivo. Mol Cell Biol 24:7024-7031. CrossRef Medline

Chou JL, Shenoy DV, Thomas N, Choudhary PK, Laferla FM, Goodman SR, Breen GA (2011) Early dysregulation of the mitochondrial proteome in a mouse model of Alzheimer's disease. J Proteomics 74:466-479. CrossRef Medline

Cras P, Smith MA, Richey PL, Siedlak SL, Mulvihill P, Perry G (1995) Extracellular neurofibrillary tangles reflect neuronal loss and provide fur- ther evidence of extensive protein cross-linking in Alzheimer disease. Acta Neuropathol 89:291-295. CrossRef Medline

David DC, Hauptmann S, Scherping I, Schuessel K, Keil U, Rizzu P, Ravid R, Dröse S, Brandt U, Müller WE, Eckert A, Götz J (2005) Proteomic and functional analyses reveal a mitochondrial dysfunction in P301L tau transgenic mice. J Biol Chem 280:23802-23814. CrossRef Medline

Dubey M, Chaudhury P, Kabiru H, Shea TB (2008) Tau inhibits anterograde axonal transport and perturbs stability in growing axonal neurites in part by displacing kinesin cargo: neurofilaments attenuate taumediated neurite instability. Cell Motil Cytoskeleton 65:89-99. CrossRef Medline

Dujardin S, Lécolle K, Caillierez R, Bégard S, Zommer N, Lachaud C, Carrier S, Dufour N, Aurégan G, Winderickx J, Hantraye P, Déglon N, Colin M, Buée L (2014) Neuron-to-neuron wild-type Tau protein transfer through a trans-synaptic mechanism: relevance to sporadic tauopathies. Acta Neuropathol Commun 2:14. CrossRef Medline

Duyckaerts C, Delatour B, Potier MC (2009) Classification and basic pathology of Alzheimer disease. Acta Neuropathol 118:5-36. CrossRef Medline

Ebneth A, Godemann R, Stamer K, Illenberger S, Trinczek B, Mandelkow EM, Mandelkow E (1998) Overexpression of tau protein inhibits kinesin-dependent trafficking of vesicles, mitochondria, and endoplasmic reticulum: implications for Alzheimer's disease. J Cell Biol 143:777794. CrossRef Medline

Eckert A, Schulz KL, Rhein V, Götz J (2010) Convergence of amyloid- $\beta$ and tau pathologies on mitochondria in vivo. Mol Neurobiol 41:107-114. CrossRef Medline

Eitan E, Tichon A, Daniel G, Priel E (2012a) Telomerase expression in adult and old mouse Purkinje neurons. Rejuvenation Res 15:206-209. CrossRef Medline

Eitan E, Tichon A, Gazit A, Gitler D, Slavin S, Priel E (2012b) Novel telomerase-increasing compound in mouse brain delays the onset of amyotrophic lateral sclerosis. EMBO Mol Med 4:313-329. CrossRef Medline

Falchetti ML, Larocca LM, Pallini R (2002) Telomerase in brain tumors. Childs Nerv Syst 18:112-117. CrossRef Medline

Fath T, Eidenmüller J, Brandt R (2002) Tau-mediated cytotoxicity in a pseudohyperphosphorylation model of Alzheimer's disease. J Neurosci 22:9733-9741. Medline

Flanary BE, Streit WJ (2005) Effects of axotomy on telomere length, telomerase activity, and protein in activated microglia. J Neurosci Res 82:160171. CrossRef Medline

Fu W, Killen M, Culmsee C, Dhar S, Pandita TK, Mattson MP (2000) The catalytic subunit of telomerase is expressed in developing brain neurons and serves a cell survival-promoting function. J Mol Neurosci 14:3-15. CrossRef Medline

Fu W, Lu C, Mattson MP (2002a) Telomerase mediates the cell survivalpromoting actions of brain-derived neurotrophic factor and secreted amyloid precursor protein in developing hippocampal neurons. J Neurosci 22:10710-10719. Medline

Fu W, Lee J, Guo Z, Mattson MP (2002b) Seizures and tissue injury induce telomerase in hippocampal microglial cells. Exp Neurol 178:294-300. CrossRef Medline

Giustiniani J, Chambraud B, Sardin E, Dounane O, Guillemeau K, Nakatani H, Paquet D, Kamah A, Landrieu I, Lippens G, Baulieu EE, Tawk M (2014) Immunophilin FKBP52 induces Tau-P301L filamentous assembly in vitro and modulates its activity in a model of tauopathy. Proc Natl Acad Sci U S A 111:4584-4589. CrossRef Medline

Götz J, Ittner LM (2008) Animal models of Alzheimer's disease and frontotemporal dementia. Nat Rev Neurosci 9:532-544. CrossRef Medline

Götz J, Probst A, Spillantini MG, Schäfer T, Jakes R, Bürki K, Goedert M (1995) Somatodendritic localization and hyperphosphorylation of tau protein in transgenic mice expressing the longest human brain tau isoform. EMBO J 14:1304-1313. Medline

Götz J, Chen F, van Dorpe J, Nitsch RM (2001) Formation of neurofibrillary tangles in P301L tau transgenic mice induced by A $\beta 42$ fibrils. Science 293:1491-1495. CrossRef Medline

Grundke-Iqbal I, Iqbal K, Tung YC, Quinlan M, Wisniewski HM, Binder LI (1986) Abnormal phosphorylation of the microtubule-associated protein tau (tau) in Alzheimer cytoskeletal pathology. Proc Natl Acad Sci U S A 83:4913-4917. CrossRef Medline

Haendeler J, Hoffmann J, Brandes RP, Zeiher AM, Dimmeler S (2003) Hy- 
drogen peroxide triggers nuclear export of telomerase reverse transcriptase via Src kinase family-dependent phosphorylation of tyrosine 707. Mol Cell Biol 23:4598-4610. CrossRef Medline

Haendeler J, Dröse S, Büchner N, Jakob S, Altschmied J, Goy C, Spyridopoulos I, Zeiher AM, Brandt U, Dimmeler S (2009) Mitochondrial telomerase reverse transcriptase binds to and protects mitochondrial DNA and function from damage. Arterioscler Thromb Vasc Biol 29:929-935. CrossRef Medline

Hedgepeth CM, Conrad LJ, Zhang J, Huang HC, Lee VM, Klein PS (1997) Activation of the Wnt signaling pathway: a molecular mechanism for lithium action. Dev Biol 185:82-91. CrossRef Medline

Hutton M, Lendon CL, Rizzu P, Baker M, Froelich S, Houlden H, PickeringBrown S, Chakraverty S, Isaacs A, Grover A, Houlden H, PickeringBrown S, Chakraverty S, Isaacs A, Grover A, Hackett J, Adamson J, Lincoln S, Dickson D, Davies P, Petersen RC, Stevens M, de Graaff E, Wauters E, van Baren J, et al. (1998) Association of missense and 5'splice-site mutations in tau with the inherited dementia FTDP-17. Nature 393:702-705. CrossRef Medline

Iannilli F, Zalfa F, Gartner A, Bagni C, Dotti CG (2013) Cytoplasmic TERT associates to RNA granules in fully mature neurons: role in the translational control of the cell cycle inhibitor p15INK4B. PLoS One 8:e66602. CrossRef Medline

Jaworski T, Dewachter I, Lechat B, Croes S, Termont A, Demedts D, Borghgraef P, Devijver H, Filipkowski RK, Kaczmarek L, Kügler S, Van Leuven F (2009) AAV-tau mediates pyramidal neurodegeneration by cell-cycle re-entry without neurofibrillary tangle formation in wild-type mice. PLoS One 4:e7280. CrossRef Medline

Kang HJ, Choi YS, Hong SB, Kim KW, Woo RS, Won SJ, Kim EJ, Jeon HK, Jo SY, Kim TK, Bachoo R, Reynolds IJ, Gwag BJ, Lee HW (2004) Ectopic expression of the catalytic subunit of telomerase protects against brain injury resulting from ischemia and NMDA-induced neurotoxicity. J Neurosci 24:1280-1287. CrossRef Medline

Khandelwal PJ, Dumanis SB, Herman AM, Rebeck GW, Moussa CE (2012) Wild type and P301L mutant Tau promote neuro-inflammation and $\alpha$-Synuclein accumulation in lentiviral gene delivery models. Mol Cell Neurosci 49:44-53. CrossRef Medline

Khlistunova I, Biernat J, Wang Y, Pickhardt M, von Bergen M, Gazova Z, Mandelkow E, Mandelkow EM (2006) Inducible expression of Tau repeat domain in cell models of tauopathy aggregation is toxic to cells but can be reversed by inhibitor drugs. J Biol Chem 281:1205-1214. CrossRef Medline

Klapper W, Shin T, Mattson MP (2001) Differential regulation of telomerase activity and TERT expression during brain development in mice. J Neurosci Res 64:252-260. CrossRef Medline

Koelsche C, Sahm F, Capper D, Reuss D, Sturm D, Jones DT, Kool M, Northcott PA, Wiestler B, Böhmer K, Meyer J, Mawrin C, Hartmann C, Mittelbronn M, Platten M, Brokinkel B, Seiz M, Herold-Mende C, Unterberg A, Schittenhelm J, et al. (2013) Distribution of TERT promoter mutations in pediatric and adult tumors of the nervous system. Acta Neuropathol 126:907-915. CrossRef Medline

Lace G, Savva GM, Forster G, de Silva R, Brayne C, Matthews FE, Barclay JJ, Dakin L, Ince PG, Wharton SB (2009) Hippocampal tau pathology is related to neuroanatomical connections: an ageing population-based study. Brain 132:1324-1334. CrossRef Medline

Lee J, Sung YH, Cheong C, Choi YS, Jeon HK, Sun W, Hahn WC, Ishikawa F, Lee HW (2008) TERT promotes cellular and organismal survival independently of telomerase activity. Oncogene 27:3754-3760. CrossRef Medline

Lee J, Jo YS, Sung YH, Hwang IK, Kim H, Kim SY, Yi SS, Choi JS, Sun W, Seong JK, Lee HW (2010) Telomerase deficiency affects normal brain functions in mice. Neurochem Res 35:211-218. CrossRef Medline

Lin MT, Beal MF (2006) Mitochondrial dysfunction and oxidative stress in neurodegenerative diseases. Nature 443:787-795. CrossRef Medline

Lovell MA, Markesbery WR (2007) Oxidative DNA damage in mild cognitive impairment and late-stage Alzheimer's disease. Nucleic Acids Res 35:7497-7504. CrossRef Medline

Lu C, Fu W, Mattson MP (2001) Telomerase protects developing neurons against DNA damage-induced cell death. Dev Brain Res 131:167-171. CrossRef Medline

Mattson M, Liu D (2002) Energetics and oxidative stress in synaptic plasticity and neurodegenerative disorders. Neuromolecular Med 2:215-231. CrossRef Medline
Maurer I, Zierz S, Möller HJ (2000) A selective defect of cytochrome c oxidase is present in brain of Alzheimer disease patients. Neurobiol Aging 21:455-462. CrossRef Medline

Melov S, Adlard PA, Morten K, Johnson F, Golden TR, Hinerfeld D, Schilling B, Mavros C, Masters CL, Volitakis I, Li QX, Laughton K, Hubbard A, Cherny RA, Gibson B, Bush AI (2007) Mitochondrial oxidative stress causes hyperphosphorylation of tau. PLoS One 2:e536. CrossRef Medline

Mena R, Edwards PC, Harrington CR, Mukaetova-Ladinska EB, Wischik CM (1996) Staging the pathological assembly of truncated tau protein into paired helical filaments in Alzheimer's disease. Acta Neuropathol 91:633641. CrossRef Medline

Mirra SS, Heyman A, McKeel D, Sumi SM, Crain BJ, Brownlee LM, Vogel FS, Hughes JP, van Belle G, Berg L (1991) The Consortium to Establish a Registry for Alzheimer's Disease (CERAD), Part II. Standardization of the neuropathologic assessment of Alzheimer's disease. Neurology 41:479_ 486. CrossRef Medline

Miwa S, Jow H, Baty K, Johnson A, Czapiewski R, Saretzki G, Treumann A, von Zglinicki T (2014) Low abundance of the matrix arm of complex I in mitochondria predicts longevity in mice. Nat Commun 5:3837. CrossRef Medline

Montine TJ, Phelps CH, Beach TG, Bigio EH, Cairns NJ, Dickson DW, Duyckaerts C, Frosch MP, Masliah E, Mirra SS, Nelson PT, Schneider JA, Tha DR, Trojanowski JQ, Vinters HV, Hyman BT, Hyman BT (2012) National Institute on Aging-Alzheimer's Association guidelines for the neuropathologic assessment of Alzheimer's disease: a practical approach. Acta Neuropathol 123:1-11. CrossRef Medline

Mutisya EM, Bowling AC, Beal MF (1994) Cortical cytochrome oxidase activity is reduced in Alzheimer's disease. J Neurochem 63:2179-2184. CrossRef Medline

Perluigi M, Sultana R, Cenini G, Di Domenico F, Memo M, Pierce WM, Coccia R, Butterfield DA (2009) Redox proteomics identification of 4-hydroxynonenal-modified brain proteins in Alzheimer's disease: role of lipid peroxidation in Alzheimer's disease pathogenesis. Proteomics Clin Appl 3:682-693. CrossRef Medline

Probst A, Götz J, Wiederhold KH, Tolnay M, Mistl C, Jaton AL, Hong M, Ishihara T, Lee VM, Trojanowski JQ, Jakes R, Crowther RA, Spillantini MG, Bürki K, Goedert M (2000) Axonopathy and amyotrophy in mice transgenic for human four-repeat tau protein. Acta Neuropathol 99:469481. CrossRef Medline

Reddy PH (2011) Abnormal tau, mitochondrial dysfunction, impaired axonal transport of mitochondria, and synaptic deprivation in Alzheimer's disease. Brain Res 1415:136-148. CrossRef Medline

Rhein V, Song X, Wiesner A, Ittner LM, Baysang G, Meier F, Ozmen L, Bluethmann H, Dröse S, Brandt U, Savaskan E, Czech C, Götz J, Eckert A (2009) Amyloid- $\beta$ and tau synergistically impair the oxidative phosphorylation system in triple transgenic Alzheimer's disease mice. Proc Natl Acad Sci U S A 106:20057-20062. CrossRef Medline

Santos JH, Meyer JN, Skorvaga M, Annab LA, Van Houten B (2004) Mitochondrial hTERT exacerbates free-radical-mediated mtDNA damage. Aging Cell 3:399-411. CrossRef Medline

Saretzki G (2014) Extra-telomeric functions of human telomerase: cancer, mitochondria and oxidative stress. Curr Pharm Des 20:6386-6403. CrossRef Medline

Sayre LM, Zelasko DA, Harris PL, Perry G, Salomon RG, Smith MA (1997) 4-Hydroxynonenal-derived advanced lipid peroxidation end products are increased in Alzheimer's disease. J Neurochem 68:2092-2097. CrossRef Medline

Selkoe DJ (2012) Preventing Alzheimer's disease. Science 337:1488-1492. CrossRef Medline

Sharma NK, Reyes A, Green P, Caron MJ, Bonini MG, Gordon DM, Holt IJ, Santos JH (2012) Human telomerase acts as a hTR-independent reverse transcriptase in mitochondria. Nucleic Acids Res 40:712-725. CrossRef Medline

Shay JW, Bacchetti S (1997) A survey of telomerase activity in human cancer. Eur J Cancer 33:787-791. CrossRef Medline

Shigenaga MK, Hagen TM, Ames BN (1994) Oxidative damage and mitochondrial decay in aging. Proc Natl Acad Sci U S A 91:10771-10778. CrossRef Medline

Singhapol C, Pal D, Czapiewski R, Porika M, Nelson G, Saretzki GC (2013) Mitochondrial telomerase protects cancer cells from nuclear DNA damage and apoptosis. PLoS One 8:e52989. CrossRef Medline

Spilsbury A, Vauzour D, Spencer JP, Rattray M (2012) Regulation of NF- $\kappa$ B 
activity in astrocytes: effects of flavonoids at dietary-relevant concentrations. Biochem Biophys Res Commun 418:578-583. CrossRef Medline

Stamer K, Vogel R, Thies E, Mandelkow E, Mandelkow EM (2002) Tau blocks traffic of organelles, neurofilaments, and APP vesicles in neurons and enhances oxidative stress. J Cell Biol 156:1051-1063. CrossRef Medline

Thal DR, Rüb U, Orantes M, Braak H (2002) Phases of A $\beta$-deposition in the human brain and its relevance for the development of AD. Neurology 58:1791-1800. CrossRef Medline

Varani L, Hasegawa M, Spillantini MG, Smith MJ, Murrell JR, Ghetti B, Klug A, Goedert M, Varani G (1999) Structure of tau exon 10 splicing regulatory element RNA and destabilization by mutations of frontotemporal dementia and parkinsonism linked to chromosome 17. Proc Natl Acad Sci U S A 96:8229-8234. CrossRef Medline

Wang X, Su B, Lee HG, Li X, Perry G, Smith MA, Zhu X (2009) Impaired balance of mitochondrial fission and fusion in Alzheimer's disease. J Neurosci 29:9090-9103. CrossRef Medline

Wong-Riley MT (1989) Cytochrome oxidase: an endogenous metabolic marker for neuronal activity. Trends Neurosci 12:94-101. CrossRef Medline

Xi P, Zhou L, Wang M, Liu JP, Cong YS (2013) Serine/threonine-protein phosphatase $2 \mathrm{~A}$ physically interacts with human telomerase reverse transcriptase hTERT and regulates its subcellular distribution. J Cell Biochem 114:409-417. CrossRef Medline

Yang Y, Mufson EJ, Herrup K (2003) Neuronal cell death is preceded by cell cycle events at all stages of Alzheimer's disease. J Neurosci 23:2557-2563. Medline

Zaug AJ, Crary SM, Jesse Fioravanti M, Campbell K, Cech TR (2013) Many disease-associated variants of hTERT retain high telomerase enzymatic activity. Nucleic Acids Res 41:8969-8978. CrossRef Medline

Zhu H, Fu W, Mattson MP (2000) The catalytic subunit of telomerase protects neurons against amyloid $\beta$-peptide-induced apoptosis. J Neurochem 75:117-124. CrossRef Medline

Zilka N, Filipcik P, Koson P, Fialova L, Skrabana R, Zilkova M, Rolkova G, Kontsekova E, Novak M (2006) Truncated tau from sporadic Alzheimer's disease suffices to drive neurofibrillary degeneration in vivo. FEBS Lett 580:3582-3588. CrossRef Medline

Zilkova M, Zilka N, Kovac A, Kovacech B, Skrabana R, Skrabanova M, Novak M (2011) Hyperphosphorylated truncated protein tau induces caspase- 3 independent apoptosis-like pathway in the Alzheimer's disease cellular model. J Alzheimers Dis 23:161-169. CrossRef Medline 